\title{
Disparity Sensitivity of Neurons in Monkey Extrastriate Area MST
}

\author{
Jean-Pierre Roy, ${ }^{1,2}$ Hidehiko Komatsu, ${ }^{1, a}$ and Robert H. Wurtz ${ }^{\dagger}$ \\ 'Laboratory of Sensorimotor Research, National Eye Institute, Bethesda, Maryland 20892 and 2Department of Neurology \\ and Neurosurgery, Montreal Neurological Institute, Montreal, Quebec H3A 2B4, Canada
}

\begin{abstract}
We tested the disparity sensitivity of neurons from the medial superior temporal area (MST) in awake behaving monkeys. While the monkey looked at a fixation spot on a screen in front of it, random dot stimuli moved in the preferred direction of the cell under study, and the disparity of the dots made the stimuli appear to move in a frontoparallel plane in front of, on, or behind the screen. Over $90 \%$ of the 272 neurons studied were sensitive to the disparity of the visual stimulus. Of those disparity-sensitive cells, $95 \%$ were most responsive either to near stimuli (stimuli with crossed disparities appearing to move in front of the screen) or to far stimuli (stimuli with uncrossed disparities appearing to move behind the screen).
\end{abstract}

In a smaller sample of the disparity-sensitive cells, we found cells whose preferred direction of stimulus motion reversed as the disparity of the stimulus reversed. For example, a cell that responded best to rightward motion for near stimuli responded best to leftward motion for far stimuli. We found that $\mathbf{4 0} \%$ of the disparity-sensitive cells had this disparity-dependent direction selectivity. This disparity-dependent direction selectivity was maintained over the entire range of speeds tested $(6-56 \% / \mathrm{sec})$.

We tested whether the disparity sensitivity of the neurons indicated the distance of the stimulus from the screen where the monkey was fixating (relative depth) or the distance of the stimulus from the monkey (absolute depth) by having the monkey fixate at different depths in front of or behind the screen. For most MST neurons, the changes in vergence did not alter the disparity response, indicating that the disparity sensitivity of these neurons conveyed information on depth relative to the plane of fixation.

We conclude that the disparity characteristics of cells in the dorsomedial MST are those expected of a system serving primarily coarse rather than fine stereopsis. The correlation between disparity selectivity and direction selectivity in these neurons, as well as their other properties, suggests a role in signaling the direction of self-motion of the observer through the environment.

\footnotetext{
Received Oct. 1, 1991; revised Jan. 16, 1992; accepted Jan. 22, 1992.

We are grateful for the use of programs originally developed by Max Dürsteler and for the modification of these programs by Stephen Grubb. We are also grateful for the use of the display program developed by Dr. Urs Schwarz of the National Eye Institute. J. P. Roy was supported by a Centennial Fellowship from the Medical Research Council of Canada.

Correspondence should be addressed to Robert H. Wurtz, Ph.D., Laboratory of Sensorimotor Research, National Eye Institute, Building 10, Room 10C101, Bethesda, MD 20892

a Present address: Neuroscience Section, Electrotechnical I aboratory, 1-1-4 Umezono, Tsukuba-City, Ibaraki-ken, 305 Japan.

Copyright (C) 1992 Society for Neuroscience $0270-6474 / 92 / 122478-15 \$ 05.00 / 0$
}

Since the experiments of Wheatstone (1838), it has been recognized that we are able to estimate the depth of objects in the environment by using the horizontal disparity of the images that these objects cast on the two retinas. While small values of disparity are thought to convey information about depth around a fixated object (Barlow et al., 1967), large disparities could contribute to subdividing the environment into large regions like foreground (what is in front of the plane of fixation) and background (what is behind the plane of fixation).

The neuronal basis of stereopsis was first investigated in the striate cortex of the cat (Barlow et al., 1967; Nikara et al., 1968; Pettigrew et al., 1968). Hubel and Wiesel (1970) then identified disparity-sensitive neurons in area 18 of the monkey, and later experiments by Poggio and Fischer (1977) in the awake monkey showed that cells from the striate cortex (V1) had disparity sensitivity. Poggio and his collaborators (Poggio and Talbot, 1981; Poggio et al., 1985) subsequently found disparity sensitivity for neurons in extrastriate areas V2, V3A, and V4. Finally, Maunsell and Van Essen (1983a) demonstrated disparity sensitivity for neurons in the middle temporal area (MT), an extrastriate area where a high proportion of cells show a direction-selective response to moving stimuli. They found that the neurons from MT, just like those from V1, V2, V3A, and V4, could be subdivided into the classes of disparity sensitivity first used by Poggio and his collaborators: near cells, which respond to stimuli in front of the plane of fixation; far cells, which respond to stimuli beyond the plane of fixation; and tuned cells (excitatory and inhibitory), which respond to disparities close to the plane of fixation.

MT projects to a series of areas within the superior temporal sulcus (STS) and in the posterior parietal cortex, including the medial superior temporal area (MST) (Van Essen et al., 1981; Maunsell and Van Essen, 1983b; Ungerleider and Desimone, 1986). Recent experiments (Desimone and Ungerleider, 1986; Komatsu and Wurtz, 1988) have indicated that MST might consist of more than one region, one of them being referred to as the dorsomedial region (MSTd). Neurons in MSTd are also usually direction selective like those in MT, but they differ from them in that they prefer the motion of a large field stimulus to the motion of a small spot stimulus (Komatsu and Wurtz, 1988). Another distinguishing property of neurons that almost certainly lie in MSTd is that some neurons prefer rotation or expansion/ contraction of the stimulus in addition to motion in the frontoparallel plane (Saito et al., 1986; Graziano et al., 1990; Duffy and Wurtz, 1991a). This finding of several types of motionselective cells in MSTd led to the suggestion that these neurons might play a role in analyzing the optic flow that results from movement of a subject through the environment (Saito et al., 1986; Tanaka et al., 1989; Duffy and Wurtz, 1991a). 
In the present experiments, we investigated whether MST neurons, particularly those in MSTd, are sensitive to disparity. We used large field stimuli that appeared to move in the frontoparallel plane in front of, on, or behind the screen on which the monkey fixated. We found that most MST neurons were sensitive either to near or to far stimuli, and that in some neurons the preferred direction of stimulus motion changed as the disparity of the stimulus changed-disparity-dependent direction-selective (DDD) cells. These and other characteristics of the MSTd neurons suggest that they might contribute to the role postulated for this area in signaling the direction of self-motion.

Brief reports of these experiments have been published previously (Roy and Wurtz, 1990; Wurtz et al., 1990).

\section{Materials and Methods}

Behavioral and physiological procedures. Two monkeys (Macaca mulatta) were prepared for singlc-cell recording by surgically implanting a head holder, recording cylinders, and eye coils while the monkey was under general anesthesia (sodium pentobarbital). The monkey was given analgesia during the postsurgical period as needed to alleviate any discomfort. Details of these procedures have been described previously (Komatsu and Wurtz, 1988).

During the experiments, monkeys were seated in a primate chair with their heads restrained. At the end of an experimental session, which lasted several hours, the monkey was returned to its home cage. The monkey's weight was monitored daily and supplementary water and fruit given as necessary. All experimental protocols were approved by the NEI Animal Care and Use Committee and complied with U.S. Public Health Service policy on the humane care and use of laboratory animals.

Monkeys were trained to fixate a small spot of light on a tangent screen $86 \mathrm{~cm}$ in front of them while large field stimuli were projected onto the screen. A behavioral trial started when the monkey touched a bar in front of it that turned on a spot of light on the tangent screen. This fixation spot stayed on for about $3 \mathrm{sec}$, and if the monkey kept its eyes within an electronic window for eye position surrounding the fixation point, it received a liquid reward. Eye movements were recorded using the magnetic search coil technique with a resolution of $0.1^{\circ}$ (Robinson, 1963; Fuchs and Robinson, 1966). Coils were implanted in both eyes (Judge et al., 1980), a separate window was used for each eye, and if either eye left the $1^{\circ}$ window the trial was aborted. An $x-y$ display of the position of both eyes showed that on successful trials the eyes stayed within an overlapping area no larger than $0.3^{\circ}$ in diameter. The fixation spot was usually $0.2^{\circ}$ in diameter and was produced by a tungsten filament projector. The field coils of the magnetic search coil systcm (used to record eye position) surrounded the chair but allowed an unobstructed view of the screen out to $40^{\circ}$ from the center. The entire tangent screen was illuminated by the light from a tungsten filament bulb (0.1 $\mathrm{cd} / \mathrm{m}^{2}$ ) between trials.

For single-cell recording, a hydraulic microdrive (Narishige) was mounted on a recording cylinder over a trephine hole in the skull over parietal cortex. Stainless steel guide tubes were directed toward the STS and placed in the recording cylinder (Crist et al., 1988). The tips of the guide tubes were positioned 3-5 $\mathrm{mm}$ above MST, and flexible tungsten microelectrodes (Frederick Haer) were used to record single cells. In each monkey, we first identified MT by its location within the STS, by the characteristic direction selectivity of its neurons, and by the size : eccentricity ratio of its receptive fields. We then located MST by virtue of its position relative to MT and by the physiological properties of the neurons.

During the fixation period, we projected a second stimulus onto the screen in order to explore the visual characteristics of the cell under study. We first used hand-held projectors that produced spots, slits, or large field random dot patterns in order to estimate the type of visual stimulus the isolated neuron preferred, the size and location of its receptive field, and whether it was direction selective. This was done while the animal maintained fixation on the screen with both eyes so that these physiological properties were determined at a disparity close to $0^{\circ}$. Spots were about $1-1.5^{\circ}$ in diameter, slits were $1-15^{\circ}$ in length and $0.2-3^{\circ}$ in width, and the area of random dots ranged from about $30^{\circ} \times$ $15^{\circ}$ to $70^{\circ} \times 50^{\circ}$. Neuronal response during preliminary search was judged using the audio monitor and an on-line raster display.
The area of the visual receptive field was determined by oscillating the stimulus at successive points away from the center of the receptive field until the cell no longer responded. We traced the receptive field area on the screen. Receptive field sizes were compared by using the square root of the receptive field area. The eccentricity of the receptive field was the distance of the geometric center of the receptive field to the fixation point in the center of the screen. For some cells with very large receptive fields, the full extent of the receptive field could not be measured. Cells were classified as direction selective if they gave a consistent response to motion in one direction but little or no response to motion in the opposite direction. Cells were studied further only if they were direction selective to motion on the tangent screen in front of the monkey, that is, in the frontoparallel plane. We therefore would not have included in our sample neurons that only responded to circular or radial motion (Saito et al., 1986; Duffy and Wurtz, 1991a).

The behavioral tasks and the storage and display of digitized data were controlled by a real-time experimental system (REX) (Hays et al., 1982) that was run on a PDP $11 / 73$ computer.

Disparity stimuli. Disparity stimuli were generated by having the monkey wear a red filter over the right eye (wratten \#26) and a green filter over the left eye (wratten \#58), and by representing each dot on the screen by a pair of horizontally separated red and green dots. The distance between dots in a pair was constant in one random dot stimulus, and corresponded to one of seven horizontal disparities: crossed $3^{\circ}$, crossed $2^{\circ}$, crossed $1^{\circ}, 0^{\circ}$, uncrossed $1^{\circ}$, uncrossed $2^{\circ}$, uncrossed $3^{\circ}$. In some instances, 11 disparities were used to better resolve the cell response around $0^{\circ}$ : the above 7 plus crossed $0.6^{\circ}$, crossed $0.3^{\circ}$, uncrossed $0.3^{\circ}$, uncrossed $0.6^{\circ}$. The spatially separated dots $\left(0.2 \times 0.4^{\circ}\right)$ were projected on a dark background. Each dot in the display appeared at one side of the field and disappeared at the opposite boundary. Parameters of the stimulus, such as direction, speed, number of dots, field size, and the location in the visual field, could be changed independently from other parameters. All results on disparity sensitivity of the MST neurons are derived from the quantitative analysis of the responses to these stimuli.

As shown by the schematic drawing in Figure 1, dot patterns with crossed disparities appear to move in front of the screen, and are referred to as near stimuli. Those with uncrossed disparities appear to move behind the screen, and are referred to as far stimuli. The relationship between the disparity of the dots and the apparent distance of the motion from the monkey is given by the expression

$$
\alpha=2\left[\tan ^{-1}\left(\frac{i}{2 f}\right)-\tan ^{-1}\left(\frac{i}{2 d}\right)\right]
$$

where $\alpha$ is the angle of disparity (in degrees), $i$ is the interocular distance, $f$ is the distance from the midpoint between the monkey's eyes to the fixation point on the screen, and $d$ is the distance from this midpoint to the plane of the visual stimulus. As illustrated in Figure 1, for a fixation distance of $86 \mathrm{~cm}$ and an interocular distance of $3.0 \mathrm{~cm}$, the near stimulus with $1^{\circ}$ crossed disparity would appear to be $30 \mathrm{~cm}$ in front of the screen, and the uncrossed stimulus of $1^{\circ}$ disparity appeared to be $97 \mathrm{~cm}$ behind the screen. We used a $3^{\circ}$ uncrossed stimulus even though it produced a disparity that was a physiological impossibility in some cases (a distance larger than infinity).

The large field random dot stimuli (static rather than dynamic) were generated by a PC-286-based microcomputer and then, under the control of REX, back-projected onto a tangent screen using a TV projector (Sony 900). The stimulus frames were stored and then projected at 60 $\mathrm{Hz}$ interleaved onto the central region of the receptive field as mapped on the screcn. Normally, the stimulus measured $20^{\circ} \times 20^{\circ}$, but when the receptive field was smaller than $20^{\circ}$ on a side, a $10^{\circ} \times 10^{\circ}$ stimulus was used, and stimuli as large as $80^{\circ} \times 66^{\circ}$ were used for large receptive fields.

The display had the advantage of filling a large part of the visual field, which was necessary for stimulating cells in the region of MST studied. It had the disadvantage of being dim: viewed through the wratten filters over the monkeys' eyes, the spot's luminance against a dark background ranged between $0.04 \mathrm{~cd} / \mathrm{m}^{2}$ and $0.07 \mathrm{~cd} / \mathrm{m}^{2}$ for the green dots and between $0.06 \mathrm{~cd} / \mathrm{m}^{2}$ and $0.1 \mathrm{~cd} / \mathrm{m}^{2}$ for the red dots. When the experimenters viewed the stimulus through the same wratten filters worn by the monkey, however, the depth of the dot field stimulus was easily perceived. On some cells, we tested the effect of further color separation and further dimming by using the same wratten filters over the separate 


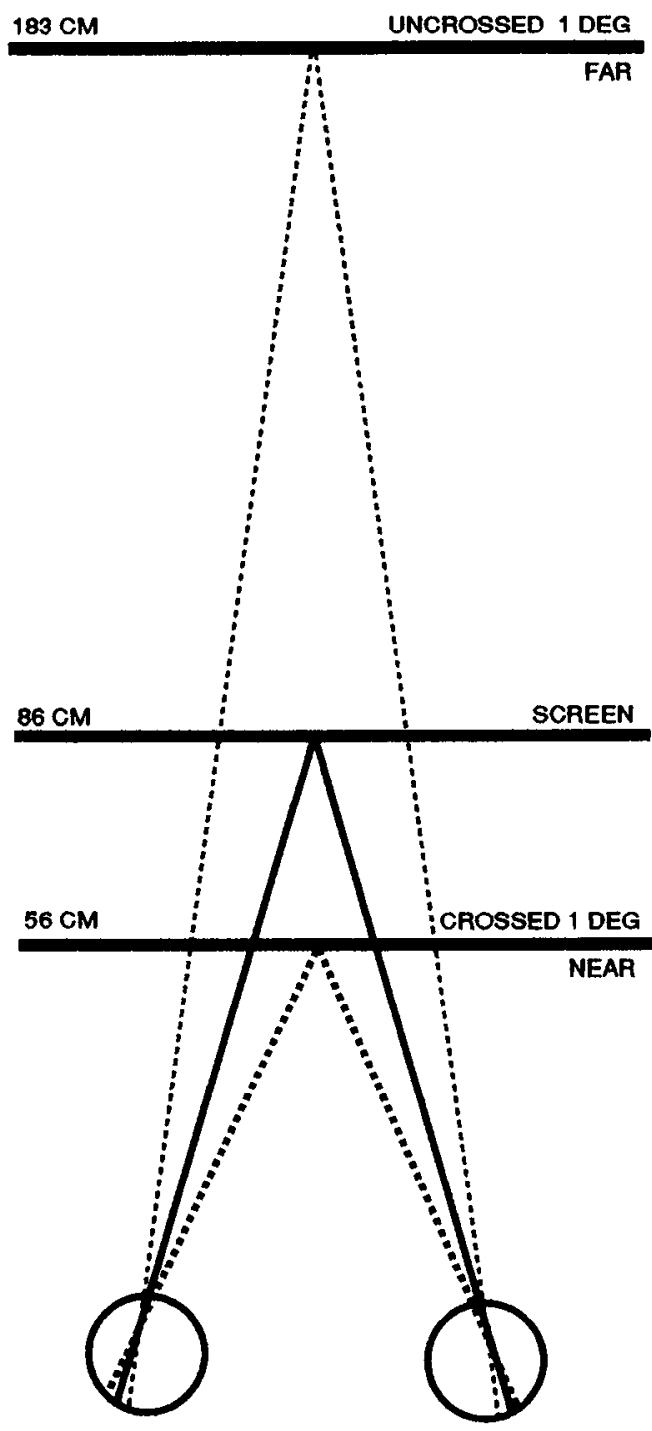

INTEROCULAR DISTANCE $3.0 \mathrm{cM}$

Figure 1. Depth of moving disparity stimuli. The monkey fixated a point on the screen $86 \mathrm{~cm}$ in front of it. A stimulus with crossed disparity appeared to move in front of the screen or $N E A R$; for a monkey with an interocular distance of $3 \mathrm{~cm}$, a stimulus of $1^{\circ}$ crossed disparity appeared to be $30 \mathrm{~cm}$ in front of the screen. A stimulus with uncrossed disparity appeared to move behind the screen or $F A R$; a stimulus of $1^{\circ}$ uncrossed disparity appeared to be $97 \mathrm{~cm}$ behind the screen. The disparity of the moving random dot stimulus was produced by the redgreen anaglyph method (see Materials and Methods).

projector guns (\#58 and \#26). This further dimmed the display but still produced the perception of depth and did not alter the disparity sensitivity of the cells tested. We do not know if more cells would have shown stronger disparity sensitivity had the stimulus been brighter. Measurements were made using a Pritchard photometer (photo research model 19808-SC) with a CIE filter and an SL10 lens with 6 min of arc aperture.

One of eight directions $\left(0^{\circ}, 52^{\circ}, 90^{\circ}, 127^{\circ}, 180^{\circ}, 232^{\circ}, 307^{\circ}\right)$ was chosen as a direction of motion in each trial. The lowest speed was usually used, but this varied slightly with the direction of motion: $6 \% \mathrm{sec}$ for $0^{\circ}$ and $180^{\circ}, 7 \% \mathrm{sec}$ for $90^{\circ}$ and $270^{\circ}, 9^{\circ} / \mathrm{sec}$ for the oblique directions. The directions and speeds of the dot fields were the same regardless of field size. Dot density was approximately one dot pair per $10^{\circ} \times 10^{\circ}$ area for dot patterns of $10^{\circ}, 20^{\circ}, 30^{\circ}$, and $40^{\circ}$ on a side. Density for the full field stimulus $\left(80^{\circ} \times 66^{\circ}\right)$ was somewhat less with one dot pair in about a $30^{\circ} \times 30^{\circ}$ area.
The set of 7 (or 11) disparity stimuli were randomly interleaved to produce blocks of $8-10$ responses per stimulus. These responses were displayed as rasters and histograms and could be examined on line. We also displayed the responses off line as rasters and spike density functions (Richmond et al., 1987). The spike density functions were produced by replacing the $1 \mathrm{msec}$ square pulse that represented each spike by a Gaussian wave with a width corresponding to a standard deviation of $3 \mathrm{msec}$. For experiments that tested for the effect of vergence, the fixation spot consisted of a combination of red and green spots produced by light emitting diodes (LEDs) (Gilway Technology \#E100 and \#E106) that were back-projected onto the tangent screen using a single-lens optical system for each LED. The spots were overlapped to produce a vergence angle of $0^{\circ}$ that placed the fixation spot on the screen or were separated by $1^{\circ}, 2^{\circ}$, or $3^{\circ}$ of arc for crossed vergence and $1^{\circ}$ or $2^{\circ}$ for uncrossed vergence. The luminance of the overlapping spots was 3.0 $\mathrm{cd} / \mathrm{m}^{2}$.

Histology. Verification of the recording sites was done in two hemispheres of one monkey. Several days before the end of the experiments, one or more electrolytic lesions ( $10 \mu \mathrm{A}$ for $10-60 \mathrm{sec}$ ) were made along penetrations through the MST areas that had been previously studied. The monkey was then deeply anesthetized with sodium pentobarbital and perfused through the heart with saline followed by $10 \%$ formalin. The posterior half of the brain was sectioned in the sagittal or the frontal plane. Every tenth section was stained with a modified silver stain (Gallyas, 1979) for myelinated fibers, and other sections were stained with thionin for cell bodies. The sites of identifiable marking lesions were plotted on drawings of the sections. Histology from the other monkey is not yet available.

\section{Results}

We recorded from 272 neurons in three hemispheres of two monkeys. These neurons all responded to planar motion on the screen in front of the monkey and were direction selective. They had receptive fields ranging in size from $4^{\circ}$ on a side to more than $80^{\circ}$ on a side.

By physiological criteria, 157 of these cells were in the dorsomedial area of MST referred to as MSTd (Komatsu and Wurtz, 1988). These neurons were direction selective, had large receptive fields for a given eccentricity (size : eccentricity ratio $>1.3$ ), had receptive fields that included or came close to the fovea (proximal edge $\leq 3^{\circ}$ from the fixation point), and had a preference for large field stimuli such as random dot patterns. We also recorded from 115 neurons in an intermediate area between MSTd and a more ventrolateral region in MST referred to as MSTl (Komatsu and Wurtz, 1988). In this intermediate region, an area we will call MSTi, the receptive fields of cells did not come within $3^{\circ}$ of the fovea and large field stimulation was not necessarily the best stimulus, but other properties of the neurons were the same as those in MSTd.

The small marking lesions made at the end of the experiments were found to lie in or more ventral and lateral to the densely myelinated area on the anterior bank of the STS that is an established part of MST (Newsome and Wurtz, 1982; Desimone and Ungerleider, 1986).

\section{Disparity sensitivity}

We considered a cell to be sensitive to disparity if it responded differently for moving stimuli having different horizontal disparities. Figure 2 shows an example of the response of a disparity-sensitive neuron when the random dot stimulus moved in the frontoparallel plane in the preferred direction and speed of the neuron. In Figure $2 A$, the disparity of the moving stimulus was uncrossed $\left(2^{\circ}\right)$; this corresponds to stimulus motion behind the point of fixation, a "far" stimulus. The response to this disparity was an increase in discharge rate above the spontaneous level as indicated on the adjacent raster and spike density plots. A small initial phasic response was followed by a tonic 


\section{A Far}
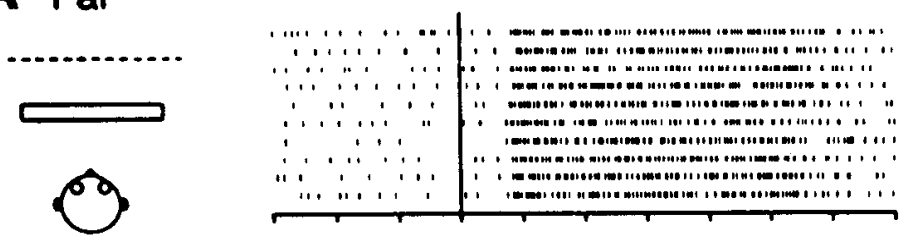

\section{B Screen}
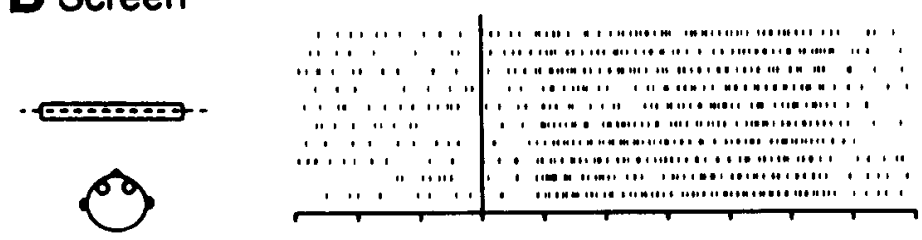

\section{Near}

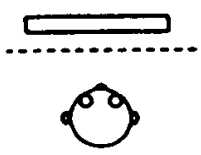

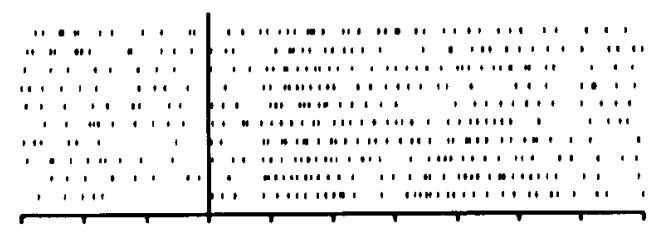

$200 \mathrm{~ms}$
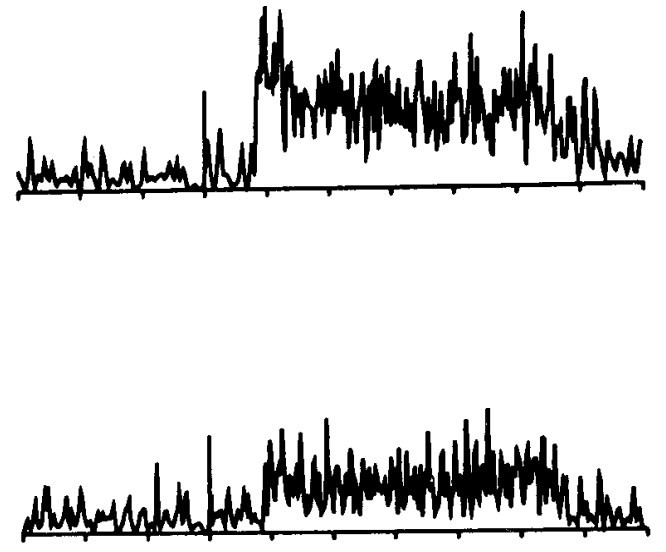



Figure 2. Response of an MSTd neuron maximally sensitive to far stimuli. Rasters (middle column) and spike density functions (right column) are shown for one cell at three different disparities. Disparity of the random dot stimulus was uncrossed $2^{\circ}(A), 0^{\circ}(B)$, or crossed $2^{\circ}(C)$. The cell discharged at a high level for uncrossed disparity corresponding to motion behind the screen (Far), it responded at a moderate level for zero disparity corresponding to motion on the screen, and it responded poorly for crossed disparity corresponding to motion in front of the screen (Near). The solid bar under the spike density function indicates the time period $(400-1000 \mathrm{msec})$ after the stimulus onset (indicated by the vertical bar) over which cell discharge was counted to produce the quantification used in subsequent analysis. The neuron shown here was in MSTd and had an RF of $18^{\circ}$ on a side and an eccentricity of $10^{\circ}$.

response that lasted for the duration of the $1000 \mathrm{msec}$ stimulus. The same cell gave a moderate response to a stimulus with no disparity, which corresponds to motion on the screen (Fig. 2B), but only a weak response to a stimulus of $2^{\circ}$ crossed disparity $\left(-2^{\circ}\right)$, which corresponds to motion in front of the fixation point, a "near" stimulus (Fig. $2 C$ ). The cell clearly responded preferentially to far stimuli.

Near and far neurons. Of the disparity-sensitive neurons we studied in MSTd and MSTi, most were either far or near cells, using the classification of Poggio and Fischer (1977). Figure 3 illustrates an example of these two disparity types. The disparity tuning curves show the mean and SE of the tonic discharge of the cells between 400 and $1000 \mathrm{msec}$ after stimulus onset. We excluded from this and all subsequent analyses the response in the first 400 msec because many cells showed a vigorous response to the onset of even stationary stimuli, as described previously (Duffy and Wurtz, 1991). In Figure $3 A$, the disparity tuning curve for a near cell shows a discharge above the spontaneous rate for crossed disparities (negative on the abscissa) from $-3^{\circ}$ to $-0.6^{\circ}$. In contrast, the far cell shown in Figure $3 B$ discharged above the spontaneous rate primarily for uncrossed disparities (positive on the abscissa).

In order to quantify the preference for near and far tuning, we calculated a disparity index using the following formula; disparity index $=1-(N-S) /(P-S)$, where $P$ is the average of the discharge rates for the preferred disparities (crossed or uncrossed), $N$ is the average of the discharge rates for the nonpreferred disparities, and $S$ is the average of the spontaneous discharge rates (during the $600 \mathrm{msec}$ before stimulus onset). The larger the disparity index, the larger the difference in the response to crossed and uncrossed disparities. The histogram in Figure 4 shows the distribution of this disparity index for 252 neurons for which we had a complete set of data points. We took a disparity index of 0.2 or more (vertical dotted line in Fig. $4 A$ ) as indicating scnsitivity to disparity, and Figure $4 B$ shows a cell with this disparity index. Near and far cells were about equally represented. The index for $88 \%$ of the neurons ( 223 cells) fell between 0 and 1.0, meaning that in most cells the disparity sensitivity was due to an increase of the discharge rate for the preferred disparities while the nonpreferred response was at or above the level of the spontaneous activity. In the remaining $12 \%$ of the neurons ( 29 cells), the disparity index was above 1 , indicating that the disparity sensitivity was due to both an increased response for the preferred disparities and a suppression of the cell response for the nonpreferred disparities.

To measure how sharp the transition from preferred to nonpreferred disparities was in the near and far neurons, we examined the slope of the curve at the transition between near and far points. Figure 5 shows the mean values in 172 near or far neurons for which we had the responses for at least seven 

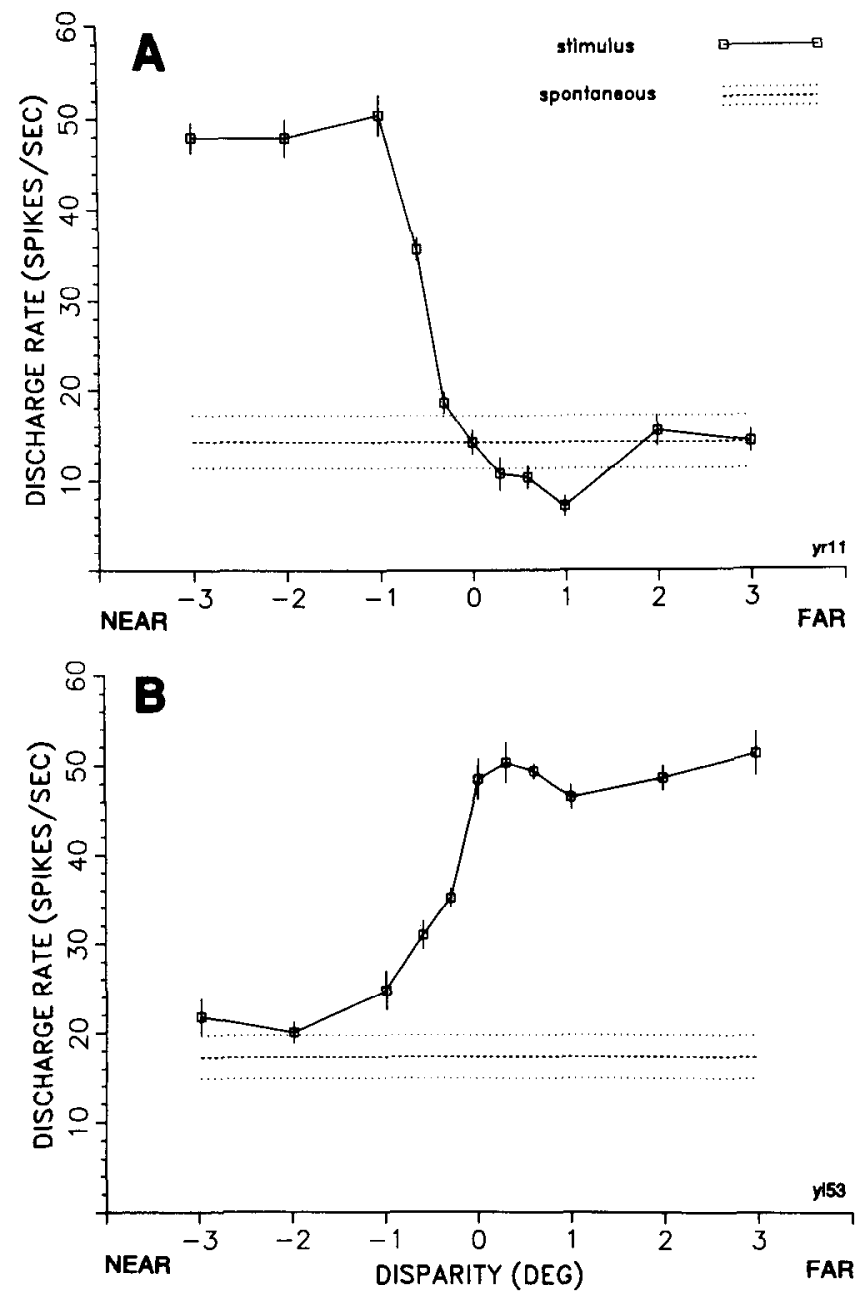

Figure 3. Disparity sensitivity of a near cell $(A)$ and a far cell $(B)$. In $A$, the neuron responds to moving stimuli with crossed disparities, from $-3^{\circ}$ to $-0.6^{\circ}$. In $B$, the neuron responds to stimuli with uncrossed disparities, from $0^{\circ}$ to $3^{\circ}$. Means and SE are shown for the discharge rate at each disparity of the stimulus. The analysis of the discharge rate included the period between 400 and $1000 \mathrm{msec}$ after stimulus onset. The stimuli moved in the frontoparallel plane and in the preferred direction at 11 disparities from crossed $3^{\circ}\left(-3^{\circ}\right)$ to uncrossed $3^{\circ}\left(+3^{\circ}\right)$. For both cells, each value is the mean of 10 responses. On this and all subsequent graphs, the means and SE of the spontaneous discharge rate are indicated by the dotted lines and are derived from the $600 \mathrm{msec}$ period before stimulus onset taken across all trials.

disparities. The mean slope of the curve at the transition from near to far is similar for the near and the far cells: 26 spikes/ sec/degree. The transition zone for the near and far cells is not symmetrical around $0^{\circ}$ disparity, however, since the corner point of the preferred response for near cells (near corner) is at $-1.1^{\circ}$ and that for far cells (far corner) is at $0.5^{\circ}$. The transition zone is shifted toward the near disparities as is also indicated by taking the midpoint of the slope: $-0.2^{\circ}$ for the near cells, and $-0.3^{\circ}$ for the far cells. This finding indicates that far cells are more often stimulated by motion at zero disparity than are near cells.

Tuned neurons. Tuned cells with no near or far component were rare. Figure $6 A$ shows an example of a cell with the largest response to stimuli moving at zero disparity. The width of the peak around zero disparity tuning was broad, extending in this case from about $-0.6^{\circ}$ to $+1.0^{\circ}$. A response more commonly
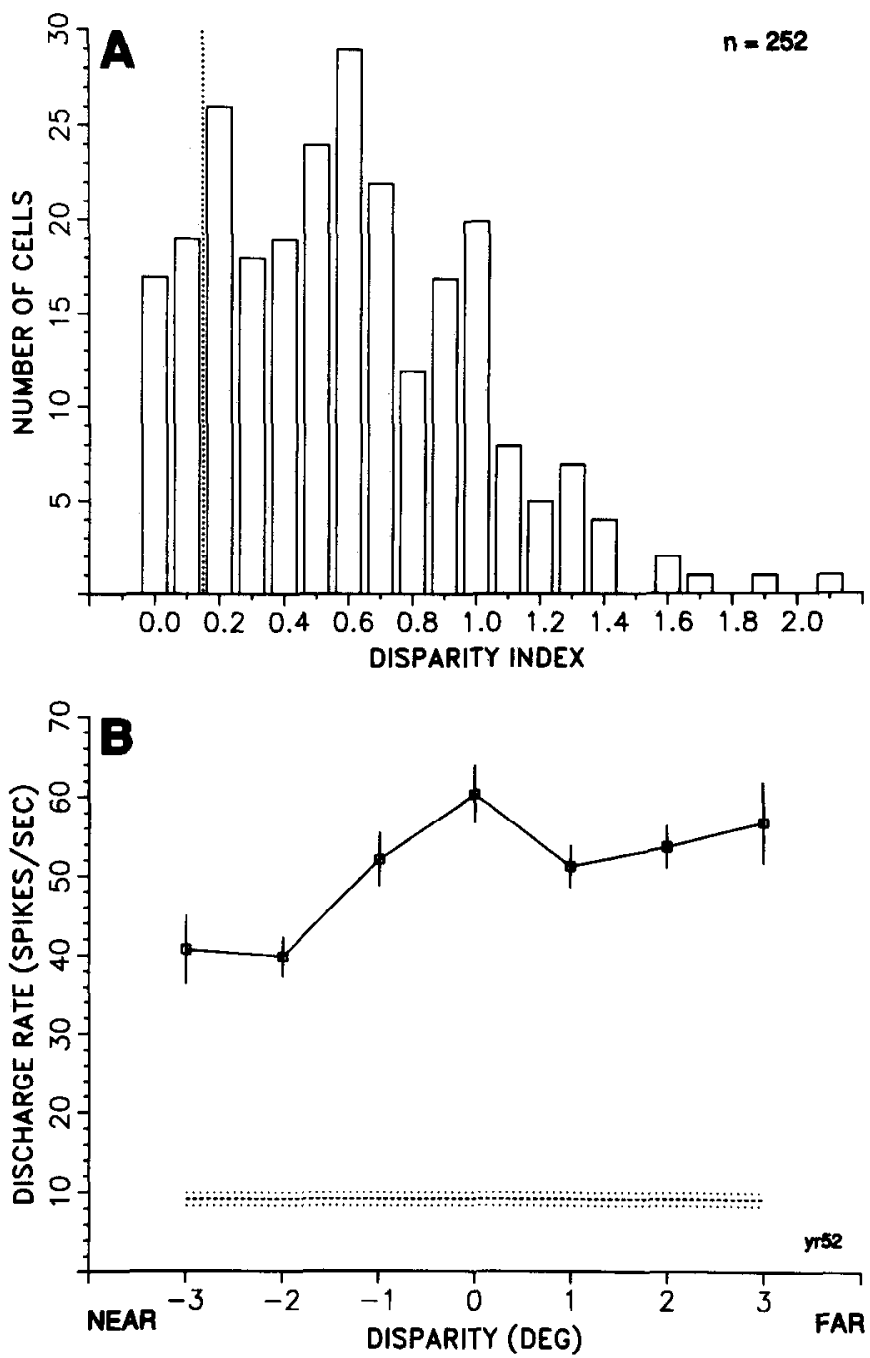

Figure 4. A, Distribution of the disparity index for a sample of 252 cells. Cells to the right of the dotted vertical line $(0.2)$ we classified as near or far cells. See Results for derivation of the index. $B$, An example of a neuron with a disparity index of 0.2 . Each value is the mean of 10 responses.

observed was one we called a mixed response: a clear far or near response with a superimposed tuned response for disparities around $0^{\circ}$. The example in Figure $6 B$ shows an increased response from $-0.3^{\circ}$ to $+0.6^{\circ}$ in addition to the increased response to far stimuli.

In order to quantify the relative strengths of tuned and nearfar responses, we calculated a relative zero index: relative zero index $=(Z-S) /(M-S)$, where $Z$ is the discharge rate for $0^{\circ}$ disparity, $M$ is the maximal discharge rate for any nonzero disparity $\left(-3^{\circ},-2^{\circ},-1^{\circ}, 1^{\circ}, 2^{\circ}\right.$, or $\left.3^{\circ}\right)$, and $S$ is the mean spontaneous discharge rate. A relative zero index above 1 indicates that the response to $0^{\circ}$ disparity is higher than that for any other disparity. Figure 7 shows the distribution of relative zero index values for 228 neurons ( 252 neurons with sufficient data minus 24 with no disparity sensitivity). Of these neurons, $76 \%$ had a relative zero index below 1 , indicating no tuned response, while $24 \%$ had a relative zero index above 1 , indicating a tuned response.

Frequency of near, far, and tuned neurons. In order to determine the frequency of the types of disparity responses seen in MST, we used the disparity and relative zero indexes to classify 


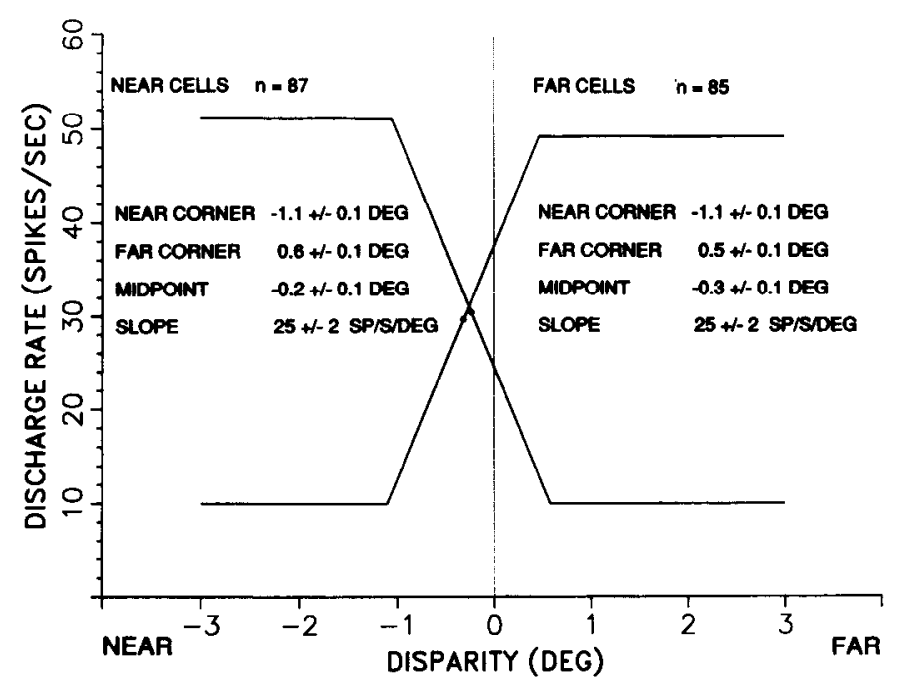

Figure 5. Comparison of the transitional zone of the disparity tuning curves for near neurons versus far neurons. All values shown are mean values for a sample of 87 near cells (left side) and 85 far cells (right side). Notice that the disparity curves for both near cells and far cells are slightly shifted toward crossed disparities rather than falling at $0^{\circ}$ disparity. The deviation of the physiological horopter from the ViethMuller circle in the crossed direction could contribute to this shift. To obtain these mean values for a near cell, the near corner point was taken where the response to near stimuli remained high before declining toward no response or inhibition for far stimuli, and the far corner point where this null response was established. For far neurons, the tuning curve was reversed so that the far corner was the point where the cell responded and the near corner point was where it did not. The slope shows the mean change in discharge rate between the near and far corner points, and the midpoint gives the mean discharge rate at the midpoint between these corner points. For purposes of illustration, the background rate is shown as 10 spikes/sec.

the cells as described in Table 1 . Over $90 \%$ of the neurons studied in the two areas (MSTd and MSTi, 228 of 252 cells) were sensitive to disparity using the disparity index of 0.2 as the criterion for near and far cells. If we used a more conservative index of 0.5 , the percentage of disparity-sensitive cells was $66 \%$. Of the disparity-sensitive neurons (using the 0.2 criterion), $95 \%$ responded to either ncar or far stimuli (216 of 228 cells). Of these 216 cells, $42(19 \%)$ also had a tuned component (mixed cells in Table 1). Pure tuned cells, those that responded only to disparities around zero (Poggio and Talbot, 1981; Maunsell and Van Essen, 1983), were rare (5\%). Only 1 of the 12 cells was a tuned inhibitory neuron (with cell discharge below background at $0^{\circ}$ disparity). Because of the similarity in disparity sensitivity between MSTd and MSTi (Table 1), we will group cells from the two areas together in the subsequent analysis. We will also concentrate on the near and far cells.

Visual characteristics. We investigated several characteristics of the MST cells to determine whether the cells showing disparity sensitivity had unique properties. Table 2 compares directional preferences of disparity-sensitive and -insensitive cells. There is a preponderance of neurons preferring motion toward the contralateral side in the disparity-sensitive cells. Also, motion along the vertical axis is underrepresented among disparitysensitive cells. We found no difference in the ratio of receptive field size to eccentricity between the different disparity classes.

\section{Disparity-dependent direction selectivity}

So far we have considered the response to disparity stimuli moving in the preferred direction of the neuron determined at
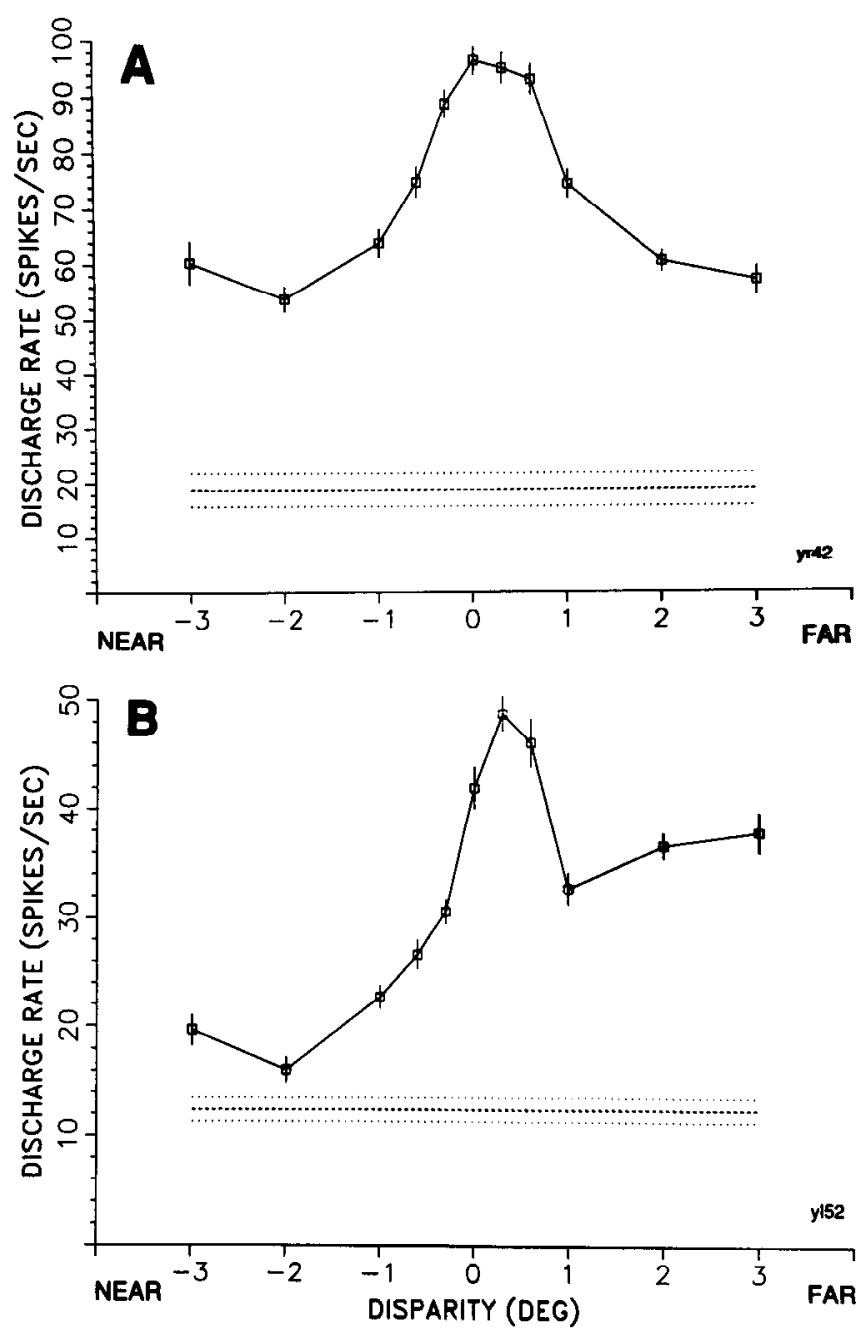

Figure 6. Example of neurons with the strongest tuned responses observed. In $A$, the cell responded best for disparities around $0^{\circ}$. The cell was classified as a tuned cell in Table 1 . In $B$, the cell responded well to uncrossed $(F A R)$ stimuli but even better for the disparities near $0^{\circ}$ disparity. The cell was classified as a far-mixed cell in Table 1. For both cells, each valuc is the mean of 10 responses.

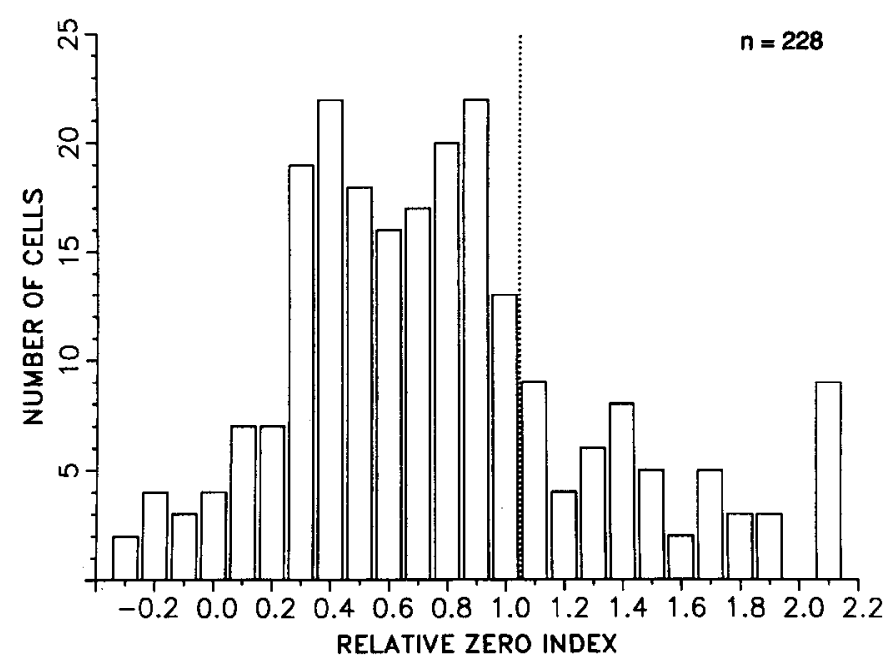

Figure 7. Distribution of the relative zero index for near-far versus tuned responses for 228 disparity-sensitive neurons. For most cells, the index is between 0 and 1 , indicating no tuned component to the response. See Results for derivation of the index. 

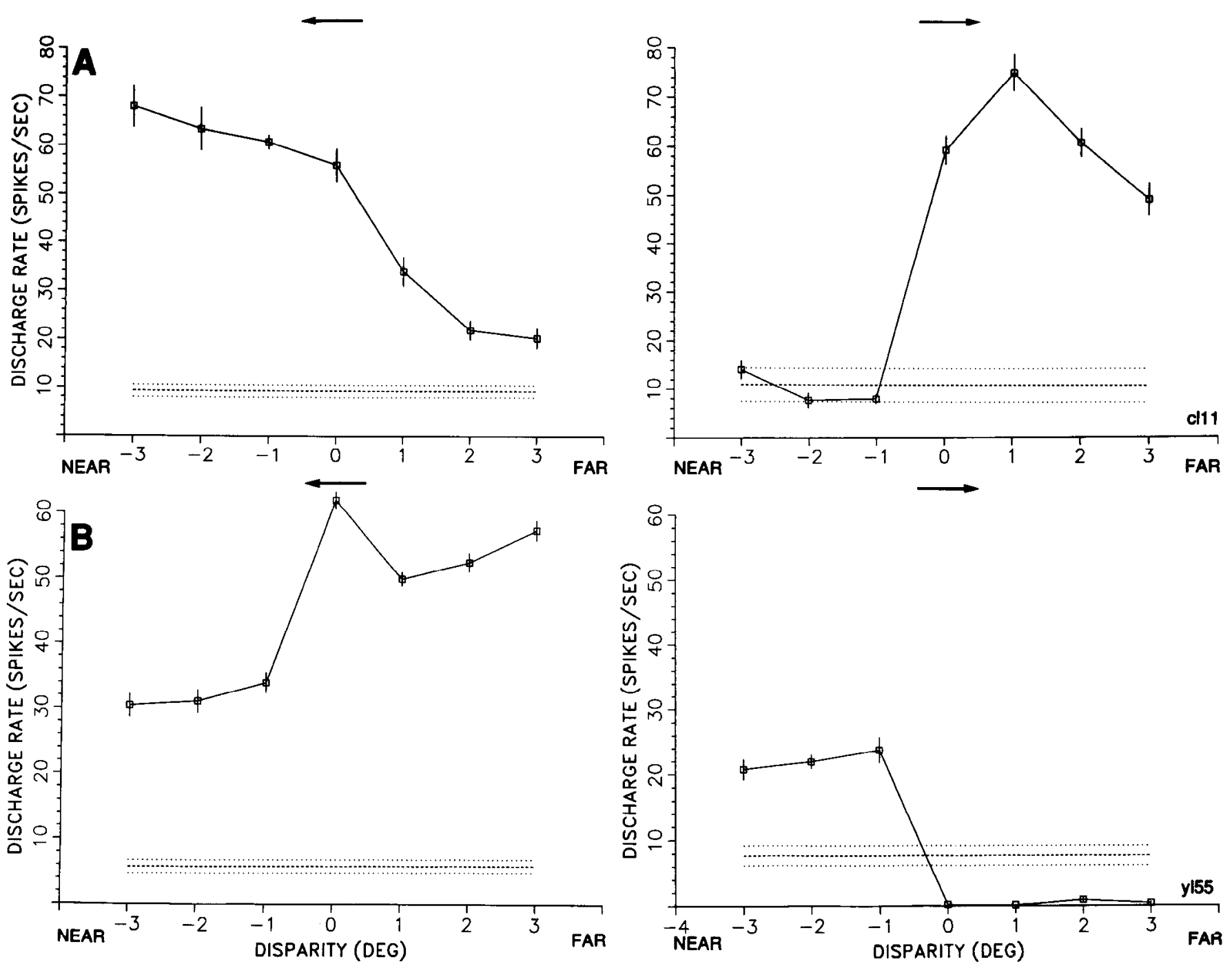

Figure 8. Examples of DDD neurons. In $A$, the neuron responded to near stimuli with stimulus motion to the left (16\%sec) but the same neuron responded to far stimuli moving in the opposite direction (to the right, $12 \% \mathrm{sec}$ ). In $B$, the cell responded to far stimuli with motion to the left $\left(6^{\circ} \%\right.$ sec) but the excitatory response was to near stimuli with motion to the right $(6 \% \mathrm{sec})$. Each value in $A$ is the mean of 5 responses; in $B$, of 10 responses.

$0^{\circ}$ disparity. In a smaller sample of 65 MST cells, we examined the response to disparity stimuli moving in both the preferred and the nonpreferred directions. We found a type of neuron that showed a DDD (disparity-dependent direction-selective) response, and we have referred to these neurons as DDD neurons (Roy and Wurtz, 1990). These neurons responded to one direction of motion for one sign of disparity (e.g., crossed) and to the opposite direction of motion for the opposite sign of disparity (uncrossed). Of the 65 neurons studied with both preferred and nonpreferred directions of motion, $40 \%$ (26 cells) were DDD cells, and two examples of DDD neurons are shown in Figure 8. In Figure $8 A$, the neuron responded to leftward motion primarily when that motion was at near disparities but to rightward motion when the stimulus was at far disparities. For the neuron shown in Figure $8 B$, the response to leftward motion was strongest for the far disparities and the response to rightward motion was excitatory for the near disparities.

Note that there was a substantial response to $0^{\circ}$ disparity for both directions of stimulus motion in the cell illustrated in Figure $8 A$. In the cell illustrated in Figure $8 B$, the response to a zero disparity stimulus was at the level of the response to the preferred (far) disparity for leftward motion only. In the 20 cells where this could be adequately measured, the response to a zero disparity stimulus was at the level of the response to both near and far stimuli in 5 cells (as in Fig. $8 A$ ), at the level of response to either near or far stimuli in 13 cells (as in Fig. $8 B$ ), and at the level of response of neither stimulus in 2 cells. We have not tested for the effect of simultaneous stimulation with motion in both preferred and nonpreferred directions.

An example of a neuron that responded to one direction of motion with stimuli at one sign of disparity and not for motion in the opposite direction (a non-DDD cell) is shown in Figure 9. Of the 65 neurons studied, $60 \%$ (39 cells) were non-DDD.

We compared the visual characteristics of DDD neurons with those of non-DDD neurons and found no difference in receptive field size, preferred disparity (near, far, tuned), ipsilateral or contralateral preferred directions, and value of the disparity or relative zero index. We looked at a number of characteristics of the cells. The most notable difference between DDD and nonDDD neurons was the larger proportion of DDD cells (62\%) 

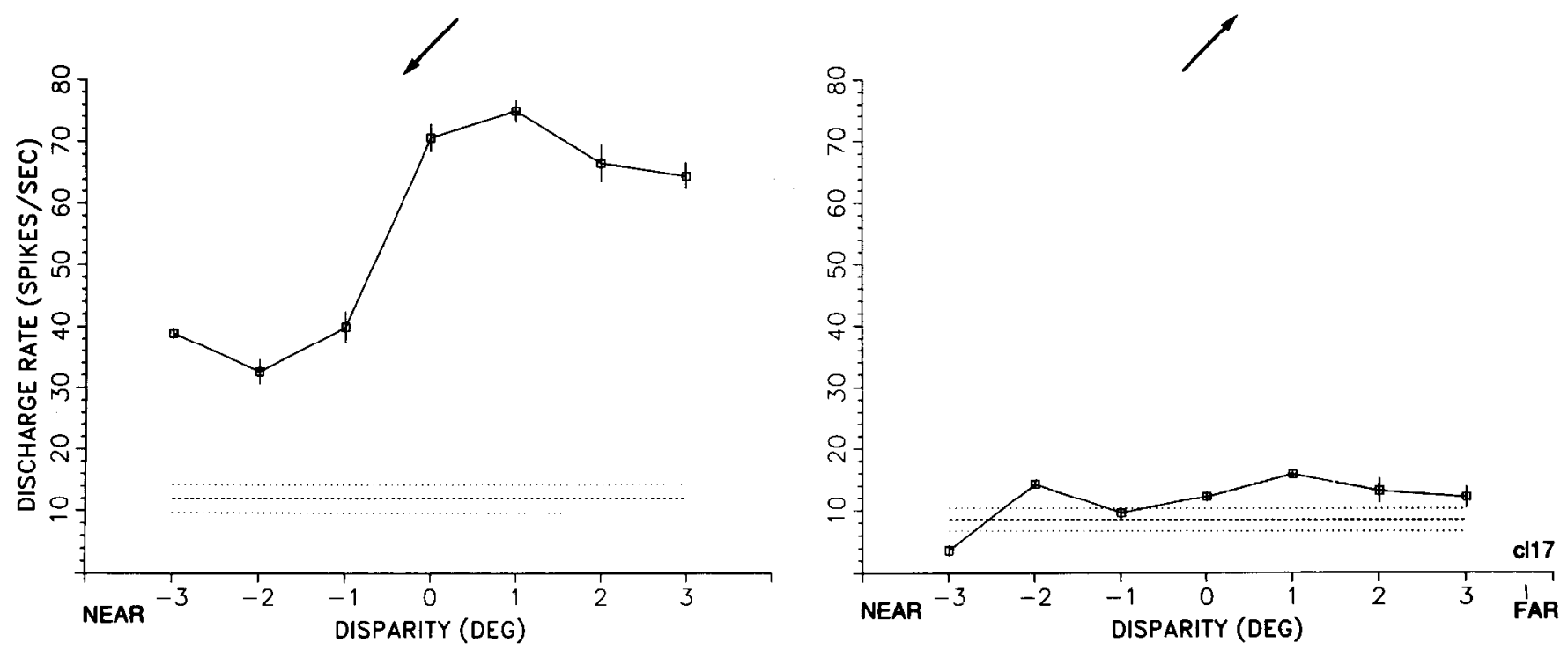

Figure 9. Example of non-DDD neuron. The neuron responded to near stimuli for one direction of stimulus motion (left and down at $9 \%$ sec) but did not respond to motion in the opposite direction (right and up at $9 \% \mathrm{sec}$ ). Each value is the mean of five responses.

that preferred motion along the horizontal axis compared to non-DDD cells $(36 \%)$.

\section{Speed sensitivity}

For the range of speeds that we tested $(6 \% \mathrm{sec}$ to $56 \% \mathrm{sec})$, the DDD characteristic of the cells remained unaltered; that is, a DDD neuron did not become a non-DDD neuron with change in stimulus speed. In the example of a DDD neuron shown in Figure 10, the neuron always preferred leftward motion for stimuli with near disparities and rightward motion for stimuli with far disparities. A common finding, however, was that the optimal speed for the two preferred directions was different. In Figure 10, the optimal speed for leftward motion is $16^{\circ} / \mathrm{sec}$ (Fig. $10 B$, left) and is $6 \%$ sec (Fig. 10A, right) for rightward motion. We had enough data points to quantify this speed effect in 20 neurons; $8 \mathrm{DDD}$ and 12 non-DDD. Of these 20 neurons, 16 had different optimal speeds for the two directions: 6 DDD (75\%) and 10 non-DDD (83\%).

There was a tendency for the DDD neurons to prefer lower speeds (average of $14 \% \mathrm{sec}$ ) compared to the non-DDD neurons (average of $32 \% \mathrm{sec}$ ), as shown in Figure 11 . This difference is significant with a $p$ of $<0.01$ (one-tailed Student's $t$ test). In contrast, no difference in preferred speed was found between near and far neurons ( $24 \pm 3 \% \mathrm{sec}$ for near cells, $23 \pm 4 \% \mathrm{sec}$ for far cells).

Finally, we examined whether the speed of stimulus motion altered the disparity with the highest discharge rate. In Figure 12 , for example, as the speed increased from $6 \%$ sec to $26 \% \mathrm{sec}$ (Fig. $12 A-C$ ), the highest discharge rate shifts from $0^{\circ}$ to $-2^{\circ}$. In order to quantify such an effect of speed on disparity sensitivity, we used two measures. In the first, we measured disparity shift with change of speed. In Figure $13 A$, a positive shift indicates that the absolute value of the preferred disparity is larger with increased speed and a negative shift indicates that the absolute value of the preferred disparity is lower with increased speed. Figure $13 \mathrm{~A}$ shows that in a majority of cases the disparity shift is positive, indicating a higher discharge rate for higher values of disparity with increased stimulus speed. Out of 37
DDD and non-DDD cell directions tested, 20 (54\%) presented a positive shift while only $4(11 \%)$ presented a negative shift. Thirty-five percent (13 of 37) showed no shift.

As a second measure of the effect of speed on disparity, we examined the ratio of the discharge rate in response to disparities with large absolute values to the discharge rate in response to disparities with small absolute values (Fig. 13B). The higher the ratio, the greater the preference for higher speeds. We again found that the most common effect of an increase in speed was that stimuli with larger absolute values of disparity produced higher discharge rates at higher speeds: $60 \%$ of the cases (22 of

Table 1. Frequency of disparity cell types

\begin{tabular}{|c|c|c|c|c|c|c|}
\hline \multirow{3}{*}{$\begin{array}{l}\text { Disparity } \\
\text { classes }^{a}\end{array}$} & \multicolumn{4}{|c|}{ Area } & & \\
\hline & \multicolumn{2}{|c|}{$\overline{\text { MSTd }}$} & \multicolumn{2}{|c|}{$\overline{\text { MSTi }}$} & \multicolumn{2}{|c|}{ Total } \\
\hline & $\%$ & $n$ & $\%$ & $n$ & $\%$ & $n$ \\
\hline Near & 42 & 63 & 34 & 35 & 39 & 98 \\
\hline Near-mixed & 4 & 6 & 7 & 7 & 5 & 13 \\
\hline Total near & 46 & 69 & 41 & 42 & 44 & 111 \\
\hline Far & 30 & 44 & 30 & 31 & 30 & 75 \\
\hline Far-mixed & 8 & 12 & 18 & 18 & 12 & 30 \\
\hline Total far & 38 & 56 & 48 & 49 & 42 & 105 \\
\hline Total near + far & 84 & 125 & 88 & 91 & 86 & 216 \\
\hline Tuned ${ }^{b}$ & 5 & 7 & 5 & 5 & 5 & 12 \\
\hline None & 11 & 17 & 7 & 7 & 9 & 24 \\
\hline Total & 100 & 149 & 100 & 103 & 100 & 252 \\
\hline
\end{tabular}

${ }^{a}$ We classified a cell as a near or far cell if the disparity index was 0.2 or more. If the averaged responses to crossed disparities were higher than for the averaged uncrossed responses, the cell was classified as a near cell, and vice versa for far cells. If a cell had a relative zero index above 1 (i.e., the largest response occurs at $0^{\circ}$ disparity), we classified it as having a tuned component. If a cell had both a disparity index of 0.2 or more and a relative zero index greater than 1.0 , we classified the cell as mixed. If the disparity index was below 0.2 and the relative zero index was above 1.0 , we classified the cell as a tuned cell. If the disparity index was below 0.2 and the relative zero index was below 1 , the cell was classified as having no disparity sensitivity.

${ }^{b}$ One tuned cell was a tuned inhibitory cell. 

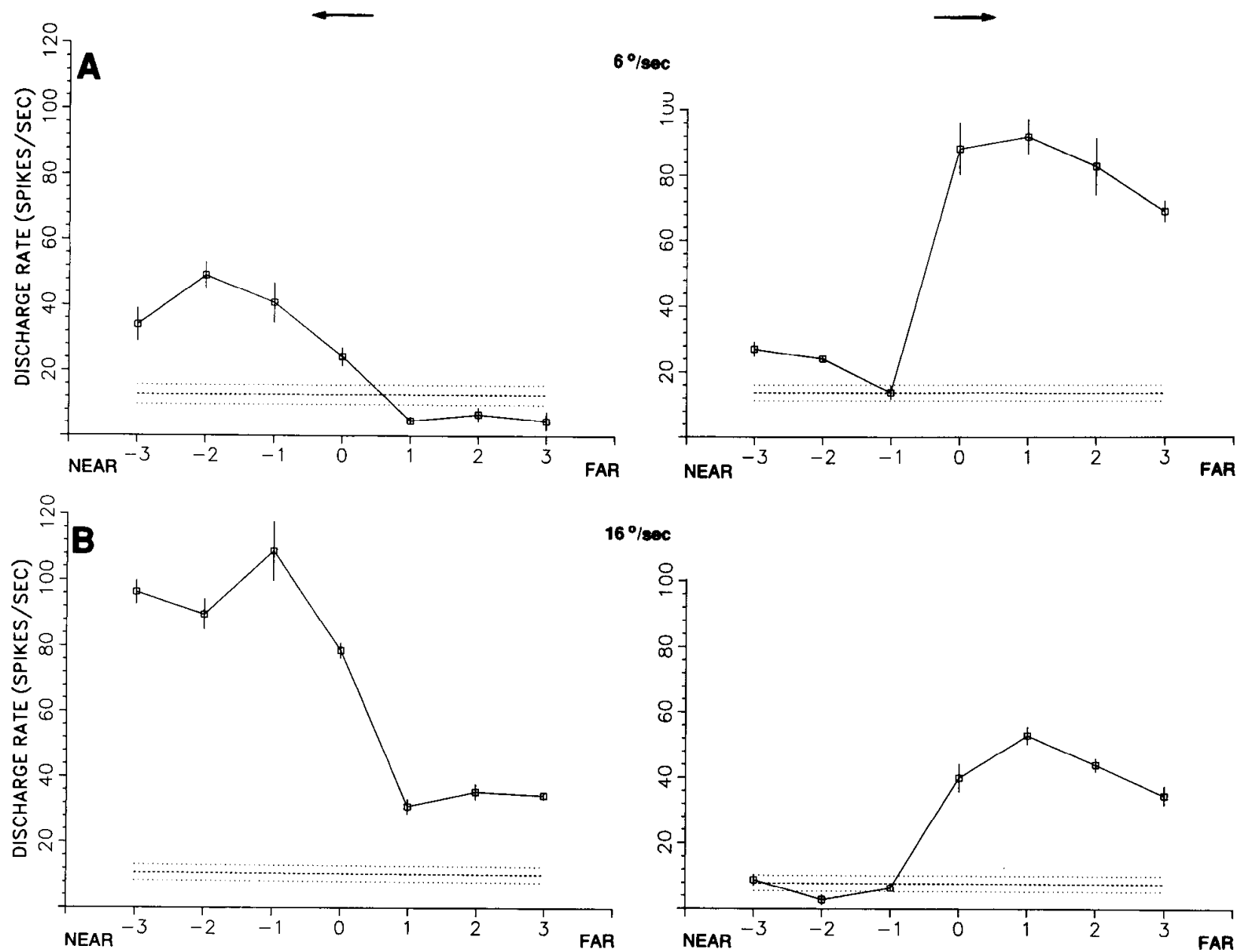

$16 \%$ soc
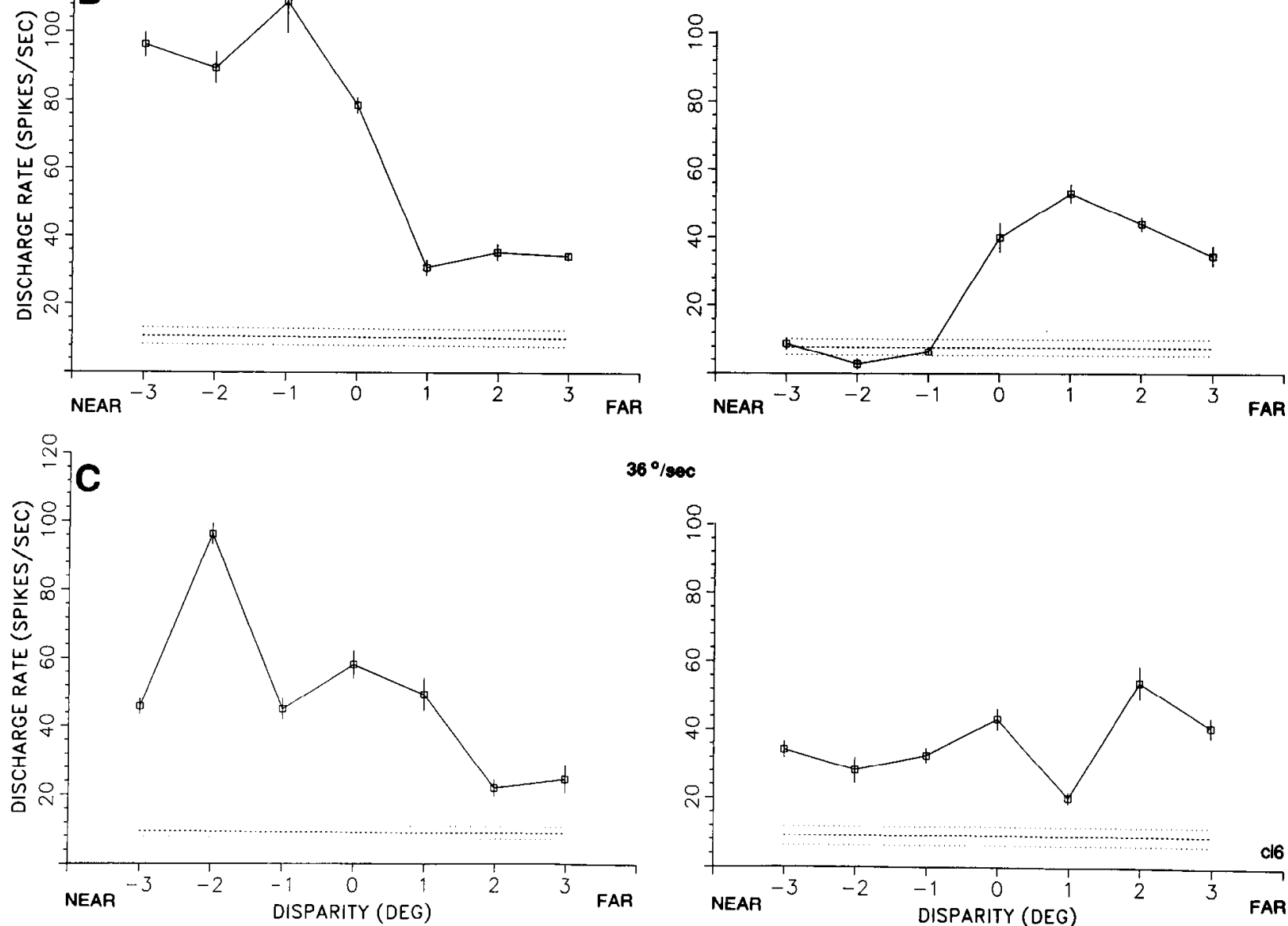

$36 \%$

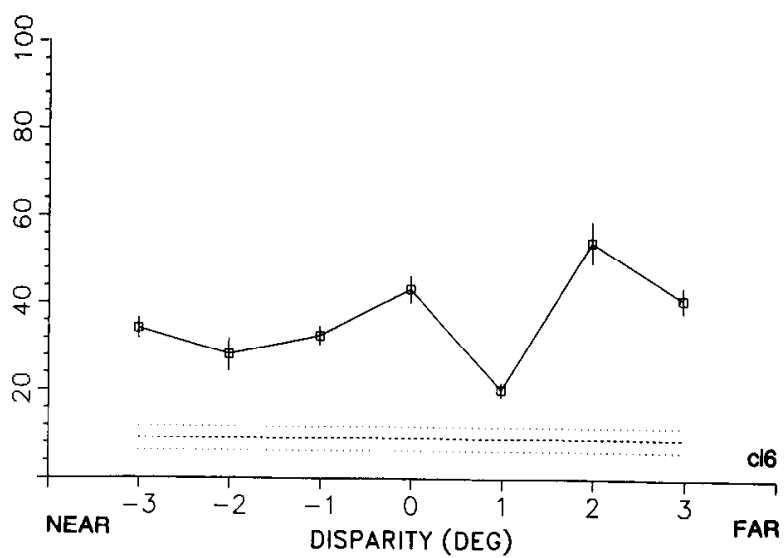

Figure 10. Response of one DDD neuron to stimuli at three different speeds: $6 \% \mathrm{sec}, 16 \% \mathrm{sec}, 36 \% \mathrm{sec}$. Stimulus motion is toward the left in the left column and toward the right in the right column. For leftward motion, the optimal response to the preferred near stimuli occurred at a speed of $16 \% \mathrm{sec}$. For rightward motion, the optimal response to the preferred far stimuli was at a different speed, $6 \%$ sec. Each value is the mean of five responses.

37) showed that effect while only $27 \%$ (10 of 37 ) showed the opposite effect. Using both measures, it appears that higher speeds favored larger absolute values of disparity.

Sensitivity to relative or absolute depth

We next examined whether these MST neurons indicate distance relative to the point of fixation or whether they signal absolute distance relative to the subject. In these experiments, we varied not only the disparity of the moving stimulus but the vergence angle as well. We first determined the preferred disparity of the cell as already described. We then shifted the depth of fixation using a red and a green fixation point, which introduced disparity into the fixation point and forced the monkey to change vergence. The disparity of the stimulus on the retina then depended 
on two factors: disparity of the stimulus and disparity of the fixation point. For example, a stimulus that produced $1^{\circ} \mathrm{crossed}$ disparity when the monkey was fixating on the screen produced $2^{\circ}$ crossed disparity at the retina when the monkey fixated on a fixation target that had $1^{\circ}$ of uncrossed disparity $\left[-1^{\circ}-\left(+1^{\circ}\right)\right.$ $=-2^{\circ}$.

We plotted the results of these experiments by using the retinal disparity of the stimulus on the abscissa of the graphs (Fig. 14). We can concentrate on three possible effects of vergence on disparity. First, vergence might have no effect, and the disparity curves generated with different vergence angles would appear superimposed as shown schematically in Figure 14A. The cell would be signaling disparity only. Second, vergence might have the effect of changing the amplitude oif the disparity curves, a gain effect as illustrated in Figure 14B. Vergence would then be modulating the disparity signal. Third, vergence could cause a shift of the disparity curves as shown in Figure $14 C$. The neuron would then be taking vergence into account and would be indicating absolute depth.

Of the 20 neurons studied, 15 showed no effect of vergence on the disparity curves, and Figure $14 D$ shows an example of such a neuron. An additional four cells showed a change in amplitude with a change in the angle of vergence, such as the example in Figure $14 E$, indicating that vergence may modulate the disparity response. Finally, the disparity curve of one neuron did shift with vergence (Fig. 14F), suggesting a shifting effect of vergence and an indication that some cells could be signaling egocentric distance. Thus, while most MST neurons carry a disparity signal unaffected by vergence, there is some indication of a modification of this signal by vergence in some neurons. Since we did not control for any changes in the accommodation that would be expected to accompany changes in vergence, such accommodation changes might have contributed to a modulation of some of the neuron's responses.

\section{Discussion}

We have made four salient observations on the disparity sensitivity of MSTd neurons. First, most neurons are sensitive to binocular disparity, and almost all are either near or far cells rather than tuned cells. Second, almost half of MSTd ncurons (the DDD cells) reverse their direction selectivity with a reversal in the sign of the stimulus disparity. Third, the responses to larger disparities tend to increase as speed increases up to the speed of about $50 \% \mathrm{sec}$ tested. Fourth, the disparity sensitivity of most neurons is independent of the vergence angle of the eye; the cells convey information about depth relative to the plane of fixation rather than distance from the subject. We think that the first observation is consistent with a role for MSTd in determining primarily whether motion is in front of or behind the plane of fixation. We will discuss how this analysis of foreground/background motion, along with the other three obser-

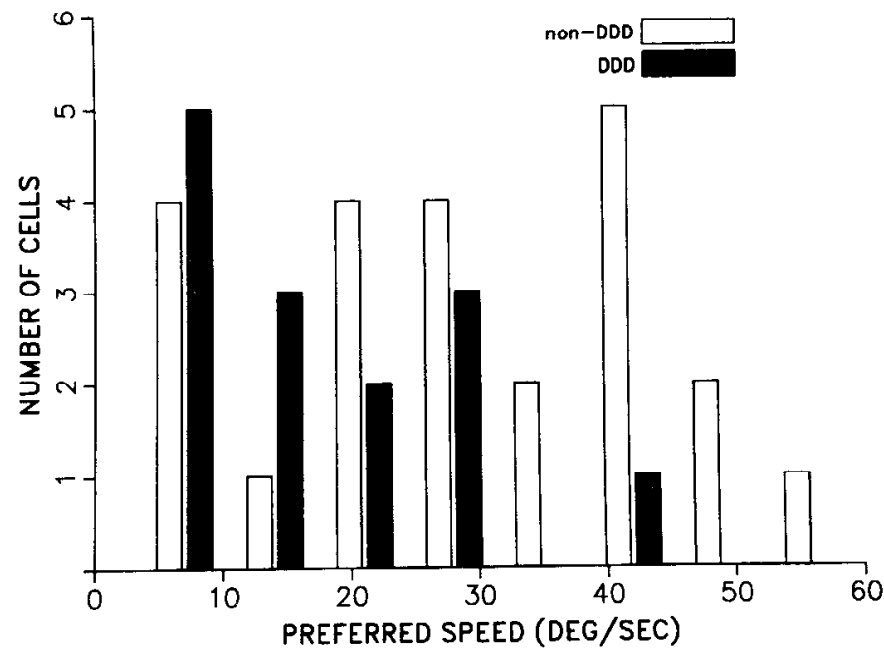

Figure 11. Distribution of preferred speeds in both DDD (solid bars) and non-DDD (open bars). DDD neurons tended to prefer lower speeds of motion than non-DDD neurons: $14 \% \mathrm{sec}$ for DDD versus $32 \% \mathrm{sec}$ for non-DDD neurons.

vations, could support a role for this area in signaling the direction and speed of self-motion.

\section{Near and far sensitivity of MSTd neurons}

The finding that the great majority of MSTd neurons are sensitive to disparity is not surprising since this area receives a direct input from MT (Maunsell and Van Essen, 1983b; Ungerleider and Desimone, 1986) where $68 \%$ of the neurons have been shown to have "pronounced" disparity sensitivity (Maunsell and Van Essen, 1983a). What is surprising is that such a high proportion (95\%) of the disparity-sensitive neurons in MSTd are either near or far cells rather than tuned cells. This is in contrast to Maunsell and Van Essen's finding of nearly equal representation of near-far and tuned cells in MT: $54 \%$ of the disparity-sensitive neurons were either near or far, and $46 \%$ were tuned. The set of disparity stimuli that we generally used resolved disparity only up to $1^{\circ}$, so we could have missed a tuned component with a tuning curve narrower than $1^{\circ}$, although we did test disparity with a resolution down to $0.3^{\circ}$ in 26 neurons and found no such narrower tuning. Even if we had missed a narrower tuning in the remaining neurons for this or some other reason, such a tuned component would have been superimposed on a near or far disparity component in $90 \%$ of the neurons studied and could have been an isolated response in only the remaining $9 \%$ of the cells that we categorized as having no disparity sensitivity.

The preponderance of cells with a near-far response suggests that MSTd cells might be most appropriate as a neural mechanism for what has been referred to as coarse rather than fine

Table 2. Physiological properties

\begin{tabular}{|c|c|c|c|c|c|c|c|c|c|c|c|}
\hline & \multicolumn{4}{|c|}{ Preferred direction $(n)$} & \multicolumn{6}{|c|}{ Preferred axis } & \multirow{3}{*}{$\begin{array}{l}\text { Number } \\
\text { of cells }\end{array}$} \\
\hline & \multirow[b]{2}{*}{ Contra } & \multirow[b]{2}{*}{ Ipsi } & \multirow[b]{2}{*}{ Up } & \multirow[b]{2}{*}{ Down } & \multicolumn{2}{|c|}{ Horizontal } & \multicolumn{2}{|c|}{ Vertical } & \multicolumn{2}{|c|}{ Oblique } & \\
\hline & & & & & $\%$ & $n$ & $\overline{\%}$ & $n$ & $\%$ & $n$ & \\
\hline Disparity & 118 & 70 & 72 & 58 & 42 & 96 & 18 & 40 & 40 & 92 & 228 \\
\hline No disparity & 8 & 7 & 8 & 8 & 25 & 6 & 37.5 & 9 & 37.5 & 9 & 24 \\
\hline
\end{tabular}



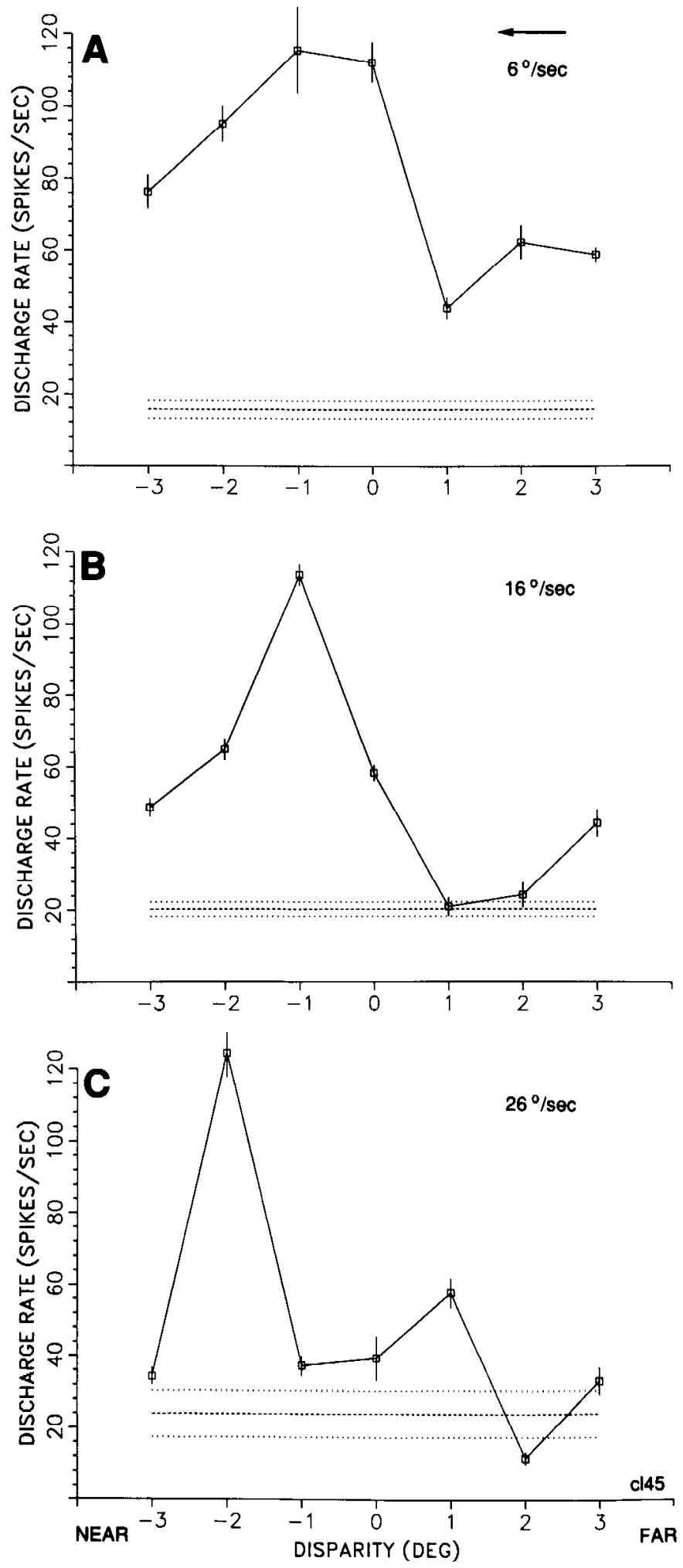

Figure 12. Illustration of a shift in the best response toward higher values of disparities as speed increases. In $A$, for stimulus motion at $6 \%$ $\mathrm{sec}$, the response of the cell was strongest at $-1^{\circ}$ and $0^{\circ}$. In $B$, with motion at $16^{\circ} / \mathrm{sec}$, the best response was at $-1^{\circ}$. In $C$, with motion at $26 \% \mathrm{sec}$, the best response was at $-2^{\circ}$. Each value is the mean of five responses.
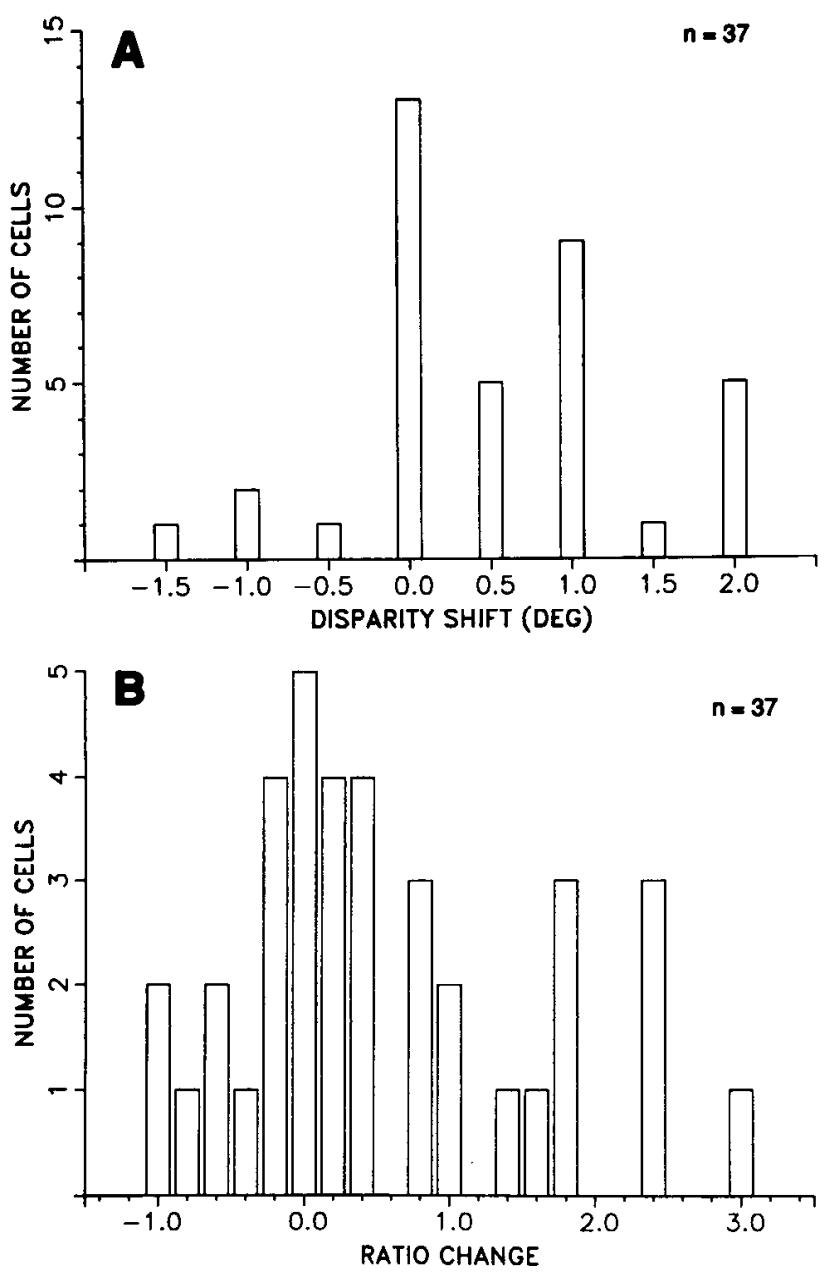

Figure 13. Effect of speed on the disparity sensitivity of the neuronal population. The graph in $A$ shows the effect of speed on the disparity shift for the 37 cell directions tested (for 12 cells each direction was treated separately). A majority of cells have a positive shift, suggesting a shift toward higher absolute values of disparity with higher speeds. This graph was constructed by first determining for each cell which value of disparity had the highest discharge rate at the lowest speed tested and which value of disparity had the highest discharge rate at the highest speed tested. The best value of disparity at the highest speed was then subtracted from the best value of disparity at the lowest speed to obtain a measure of the shift in disparity. A minimal difference of $5 \%$ in the relative discharge rate (ratio of the discharge rate for each disparity to the average discharge rate for the three preferred disparities) was used to determine which was the best disparity. $B$ shows the effect of speed on the discharge rate ratio for the 37 cell directions. A majority of cells have a positive value, again suggesting a shift toward higher values of disparity with higher speeds. For this graph, we first determined the ratio of the individual discharge rate at each disparity relative to the average discharge rate for the three preferred disparities. We then considered the ratio of discharge rates for low absolute values of disparity $\left(0^{\circ}\right.$ and $\left.1^{\circ}\right)$ and for high absolute values of disparity $\left(2^{\circ}\right.$ and $\left.3^{\circ}\right)$ separately. An increase in the ratio for high values of disparity and a decrease for low values of disparity were given a positive number while an increase in the ratio for low values of disparity and a decrease for high values of disparity were given a negative number. These numbers were then added to arrive at a measure of the change in ratio with speed. Again, a minimal difference of $5 \%$ in the ratio was used as a threshold value. The average disparity shift for DDD neurons was $+0.47^{\circ}$ and $+0.55^{\circ}$ for non-DDD neurons, and the average ratio change was +0.41 for DDD neurons and +0.77 for non-DDD neurons. The average disparity shift for near cells was $+0.54^{\circ}$ and $+0.46^{\circ}$ for far cells, and the average ratio change was +0.57 for near and +0.71 for far cells. 

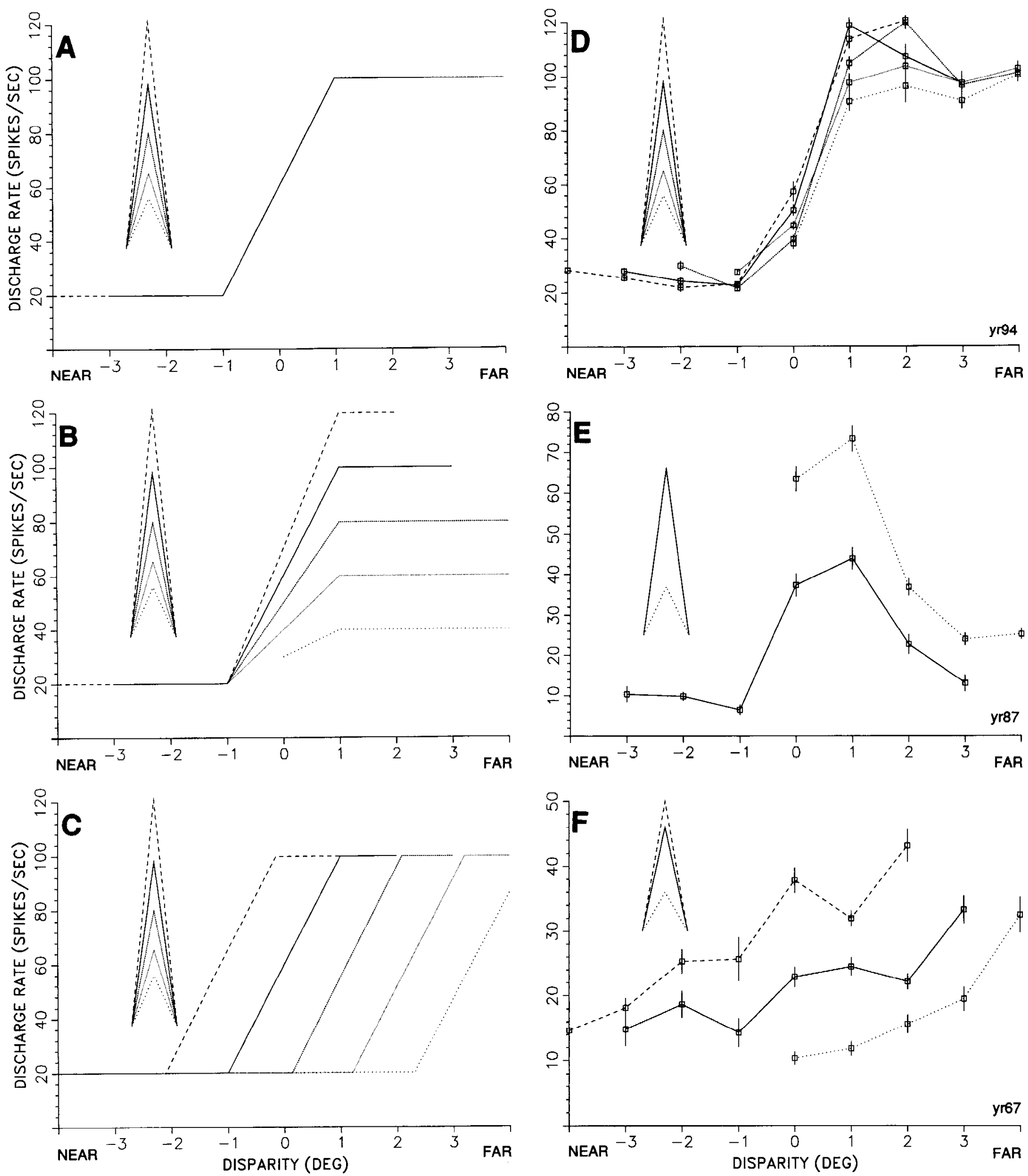

Figure 14. Effect of change of vergence on disparity sensitivity. The left column shows schematically the possible effects of vergence on disparity. In $A$, for a pure disparity neuron, the disparity curves should be exactly superimposed irrespective of the vergence. In $B$, for a cell where disparity response was modulated by a change of vergence angle, there should be a change in the amplitude of the response. In $C$, for a cell that coded distance, changes in vergence should change the preferred retinal disparity. The right column shows the observed effect of vergence on disparity in three sample cells. In $D$, the disparity curves are the same irrespective of the angle of vergence, the cell signals pure disparity. In $E$, there is a gain effect of vergence on the disparity curve. In $F$, there is a shift of the disparity curves with different angles of vergence. For all three cells, each value on the graphs is the mean of 10 responses. 


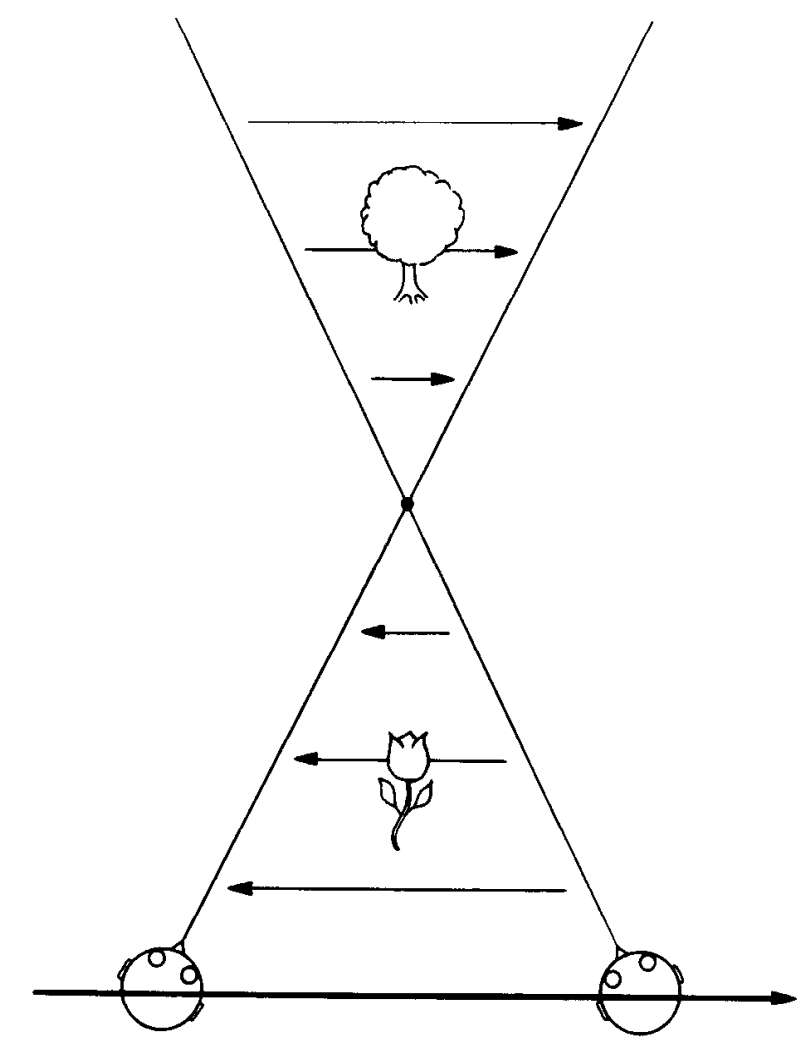

Figure 15. Opposite motions of the background and foreground during self-motion. As an observer moves to the right, the direction of motion of the images will depend on the sign of their depth relative to the point of fixation (the dot). Objects in the background "move" in the direction of self-motion: rightward in the condition illustrated here. Objects in the foreground "move" in the opposite direction, in this case, leftward. The speed of displacement of the image of the objects (indicated by the length of the arrows) will depend on the magnitude of the depth relative to the point of fixation: the farther away from this point the object is, the faster its image will "move" on the retina. The condition illustrated, one in which the angle between the direction of self-motion and the direction of gaze is very large $\left(90^{\circ}\right.$ at midtrajectory), is an unusual one but was selected for ease of description.

stereopsis (Bishop and Henry, 1971). Fine stereopsis has been defined as a precise estimate of depth made from the fused single image of an object, and it operates for quite small disparities with a maximum of about $15^{\prime}$ to $2^{\circ}$ of arc, depending on the stimulus conditions (Mitchell, 1966; Fender and Julesz, 1967). Fine stereopsis includes the patent and qualitative stereopsis of Ogle (1952a,b). Coarse stereopsis, on the other hand, is a depth discrimination based on disparities that are so large that they produce double images (Bishop and Henry, 1971). Using these double images, subjects are able to estimate whether an object is nearer or farther than the fixation plane. Disparities of up to $7-10^{\circ}$ for crossed and uncrossed disparities (Westheimer and Tanzman, 1956), and disparities as large as $7^{\circ}$ for crossed and $12^{\circ}$ for uncrossed (Blakemore, 1970), have been found to provide such depth information. The near-far cells would seem to provide an appropriate ncural mechanism for coarsc stcrcopsis since their range of disparity sensitivity is so wide, extending much beyond the minutes of arc usually associated with fine stereopsis. While this distinction between fine and coarse stereopsis was based largely on the response to stationary stimuli, we see no reason the same principle should not apply to the moving stimuli we have studied as well. The possibility that the near-far cells contribute to fine stereopsis also cannot be excluded since their transition zone (the part of the disparity tuning curve where the response shifts from preferred to null response) occurs near the plane of fixation, and this transition zone could provide information about fine stereopsis (Lehky and Sejnowski, 1990; Lehky et al., 1990).

One function that the coarse disparity characteristics of the MSTd neurons suggests is related to the initiation of vergence eye movements. For example, the near-far cells could provide information on the direction of the vergence change required to shift fixation from one point to another in depth. Vergence eye movements can also be readily initiated by disparity between unlike objects (Westheimer and Mitchell, 1969). The lack of form specificity but prominence of disparity sensitivity of MSTd neurons would be consistent with a role in vergence eye movements, and this role would be compatible with the report that cells on the medial bank of the STS and in the intraparietal sulcus discharge in relation to vergence movements and to pupillary change (Gnadt and Mays, 1989).

Another possible function of the MSTd neurons that is suggested by their coarse disparity characteristics is the analysis of the motion of the entire visual field. Such motion of the whole visual field occurs, under natural conditions, only when subjects move either their eyes, their heads, or their bodies. A common case of movement of the body occurs when the subject moves through the environment and generates a type of visual stimulation, referred to as optic flow, that is the result of the subject's own movement. The large receptive fields of the MSTd neurons, their response to motion of large patterned stimuli, and their response to the components of optic flow stimulation (Saito et al., 1986; Graziano et al., 1990; Duffy and Wurtz, 1991a) has led to the proposal that MSTd neurons play a role in analyzing the visual consequences of self-motion (Saito et al., 1986; Duffy and Wurtz, 199la). In addition, we have proposed that the disparity sensitivity of the MSTd neurons also contributes to this analysis of the visual motion stimuli generated as the subject moves through the environment (Roy and Wurtz, 1990).

\section{Contribution of disparity to the analysis of self-motion}

Figure 15 illustrates one condition of self-motion in which the subject moves in the direction of the bottom arrow (to the right), while maintaining fixation on an object off to the side (the dot). The near $90^{\circ}$ angle between the direction of the subject's motion and the direction of his gaze (eye and head) changes continuously as the subject tracks the object of interest during the self-motion. As indicated by the direction of the arrows in the figure, this condition creates motion of the background (behind the plane of fixation) in the same direction as the subject's movement and of the foreground (in front of the plane of fixation) in the direction opposite to the subject's movement. The two opposite directions are due to the geometry of the compensating gaze movement; as the subject moves in one direction, the fixation point acts as a pivot for the line of gaze, which then moves across the foreground and the background in opposite directions.

Near-far $D D D$ responses. If MSTd neurons are involved in indicating the direction of this self-motion, then they should respond to these two opposite directions of foreground and background motion. The $40 \%$ of MST neurons that are DDD cells do exactly that. They respond to opposite directions of motion for opposite disparities. We propose that this combination of one disparity with one direction and of the opposite disparity with the opposite direction allows these cells to signal the di- 
rection of motion of the subject relative to the object tracked. For example, leftward moving foreground or rightward moving background means self-motion to the right; it cannot mean selfmotion to the left.

The non-DDD neurons also provide information about selfmotion, although they do so only for motion in the foreground or background, and not both. A non-DDD far neuron discharging for a rightward moving background usually would signal self-motion to the right, but there are cases where such a nonDDD neuron would not convey such information about selfmotion. For example, a far cell sensitive to rightward motion would not discharge if the subject fixated some object at infinity. On the other hand, a DDD neuron would discharge because of its response to near stimuli. The DDD neurons provide a more general signal about the direction of self-motion.

Another potential advantage of the double signal of the DDD neurons would be if they discharged for self-motion (as in Fig. 15) but did not for pursuit eye movements, when the motion of foreground and background are in the same direction. The DDD neurons then would be specific for self-motion. In order to test this hypothesis, we would need to know the response of the DDD neurons to simultaneous presentation of foreground and background motions.

So far, we have equated one given direction of motion with one given disparity as if these two parameters were exactly correlated. In fact, the two are relatively independent phenomena. The direction of motion of what is in front and what is behind the point of fixation depends exclusively on the geometry of the compensating gaze movement, which is a monocular phenomenon; the disparity, on the other hand, depends on the convergence of the two eyes on the object of fixation, which is binocular. To a first approximation, the two points, point of gaze stabilization and point of eye convergence, can be equated, as it seems reasonable to assume that the subject will track and converge on the same object. They are not necessarily the same, however, either because of imperfect vergence or imperfect gaze stabilization. This could account for responses at the level of the preferred disparity for $0^{\circ}$ in some neurons. If the gaze compensation for the self-motion is incomplete, for example, the object fixated will move in the direction opposite to the selfmotion, that is, with the foreground. Assuming perfect vergence, the object at $0^{\circ}$ will move in the direction of foreground motion. The finding that the discharge rate for $0^{\circ}$ is more often associated with far disparities (background) would suggest that gaze overcompensation is more common than gaze undercompensation (see Fig. 5).

Higher speeds and larger disparities. Another characteristic of the visual motion generated as a subject moves through the environment is that the apparent speed of motion of objects varies with the distance from the plane of fixation. In Figure 15 , the speed of motion is indicated schematically by the length of the arrows; objects close to the plane of fixation move slowly, while objects away from this plane (nearer or farther) move faster. Therefore objects with large absolute values of disparity (those farther from the plane of fixation) should move faster, although the actual speed values will be scaled by the speed of the self-motion itself. A sensitivity of MSTd neurons to speed gradients then could indicate a role for these neurons in signaling not only the direction but also the speed of self-motion. Using single depth planes, we did find a tendency for the neurons studied to prefer larger disparities as the speed of the stimulus increased. However, it is apparent from Figure 15 that the stim- ulus to which MSTd neurons should be most sensitive is motion at multiple depth planes moving with different speeds. The role of MSTd neurons in conveying information about the characteristics of self-motion would be strengthened by the demonstration of a response to such speed gradients.

Relative depth. Another property expected of neurons that provide information about the direction of self-motion is that they should be sensitive to relative depth, the distance relative to the plane of fixation, and not to absolute depth, the distance relative to the subject. In Figure 15, if the subject chooses another object to fixate, both the plane of vergence and the plane of gaze stabilization will change together. Because of this, the disparity and direction will also vary together: leftward motion will be in the foreground, rightward motion in the background, no matter what actual distances forcground and background correspond to. It appears preferable for a system signaling selfmotion to carry a signal about depth relative to the plane of fixation and not depth relative to the subject. As we have seen, most cells in MSTd respond to pure disparity independent of angle of vergence. The neurons that did show a modulation of their response as we altered vergence, and the one neuron that appeared more closely related to absolute depth may indicate input related to vergence or accommodation. This may indicate a transition from information on disparity alone to that conveying information on absolute depth.

\section{Combination of disparity and other signals about self-motion}

We conclude that neurons in MSTd seem to have the attributes necessary for analyzing the kind of motion illustrated in Figure 15. We propose that the disparity-sensitive neurons signal the dircction of sclf-motion relative to the object fixated. The preponderance of the near neurons and far neurons, the presence of DDD neurons, the indication of a relationship between higher stimulus speeds and larger disparities, and the sensitivity to relative depth make these neurons prime candidates for this role.

We do not want to imply, however, that disparity is the only signal capable of carrying the depth information needed to compute the direction of self-motion from visual signals. In fact, Warren and Hannon (1990) have shown that the direction of self-motion can be determined from visual information in which relative speeds are the only signal about depth. Nonvisual information about self-motion is also available to the subject such as vestibular and proprioceptive inputs and corollary discharges from motor centers, and such an input has been demonstrated for MST neurons (Newsome et al., 1988). Both visual and nonvisual information are probably used either simultaneously or under different conditions. What we propose is that the type of disparity sensitivity we describe provides one mechanism that could indicate one's direction of motion in the environment by combining, at the single-cell level, the relatively low-level signals of direction of motion and disparity.

The relative importance of these mechanisms probably varies under different behavioral conditions. For example, in Figure 15 , we considered an unusual condition in order to simplify the discussion - the direction of self-motion and the direction of gaze were close to $90^{\circ}$ apart. Under this condition, the motion generated is primarily fronto-parallel, and disparity is then useful to indicate the direction of self-motion. When subjects look exactly where they are going (an angle of $0^{\circ}$ between the direction of self-motion and the direction of gaze), a radial pattern of optic flow away from the point of fixation is then prominent. 
Cells that respond specifically to such radial motion have been identified in MSTd (Saito et al., 1986; Tanaka and Saito, 1989; Duffy and Wurtz, 1991a,b). Thus, under different conditions, two neuron types identified in MSTd, DDD cells and the singlecomponent radial motion cells (Duffy and Wurtz, 1991), provide a different complementary signal about the direction of selfmotion. DDD neurons would signal the frontoparallel component: left/right or up/down, while radial cells would give the sagittal component: toward/away. The net direction of self-motion relative to the object tracked could then be computed by combining the two vectors from the two cell populations.

\section{References}

Barlow HB, Blakemore C, Pettigrew JD (1967) The neural mechanism of binocular depth discrimination. J Physiol (Lond) 193:327-342.

Bishop PO, Henry GH (1971) Spatial vision. Annu Rev Psychol 22: 119-160.

Blakemore C (1970) The range and scope of binocular depth discrimination in man. J Physiol (Lond) 211:599-622.

Crist CF, Yamasaki DSG, Komatsu H, Wurtz RH (1988) A grid system and a microsyringe for single cell recording. J Neurosci Methods 26:117-122.

Desimone R, Ungerleider LG (1986) Multiple visual areas in the caudal superior temporal sulcus of the macaque. J Comp Neurol 248: 164-189.

Duffy CJ, Wurtz RH (1991a) Sensitivity of MST neurons to optic flow stimuli. I. A continuum of response selectivity to large-field stimuli. J Neurophysiol 65:1329-1345.

Duffy CJ, Wurtz RH (1991b) Sensitivity of MST neurons to optic flow stimuli. II. Mechanisms of response selectivity revealed by small-field stimuli. J Neurophysiol 65:1346-1359.

Fender D, Julesz B (1967) Extension of Panum's fusional area in binocularly stabilized vision. J Opt Soc Am 57:819-830.

Fuchs AF, Robinson DA (1966) A method for measuring horizontal and vertical eye movement chronically in the monkey. J Appl Physiol 21:1068-1070.

Gallyas F (1979) Silver staining of myelin by means of physical development. Neurol Res 1:203-209.

Gnadt JW, Mays LE (1989) Posterior parietal cortex, the oculomotor ncar response and spatial coding in 3-D space. Soc Neurosci Abstr 15:786.

Graziano M, Andersen R, Snowden R (1990) Stimulus selectivity of neurons in macaque MST. Soc Neurosci Abstr 16:6.

Hays AV, Richmond BJ, Optican LM (1982) A UNIX-based multiple process system for real-time data acquisition and control. WESCON Conf Proc 2:1-10.

Hubel DH, Wiesel TN (1970) Cells sensitive to binocular depth in area 18 of the macaque monkey cortex. Nature 255:41-42.

Judge SJ, Richmond BJ, Chu FC (1980) Implantation of magnetic search coils for measurement of eye position: an improved method. Vision Res 20:535-538.

Komatsu H, Wurtz RH (1988) Relation of cortical areas MT and MST to pursuit eye movements. I. Localization and visual properties of neurons. J Neurophysiol 60:580-603.

Lehky SR, Sejnowski TJ (1990) Neural model of stereoacuity and depth interpolation based on a distributed representation of stereo disparity. J Neurosci 10:2281-2299.

Lehky SR, Pouget A, Sejnowski TJ (1990) Neural models of binocular depth perception. Cold Spring Harbor Symp Quant Biol 55:765-777.

Maunsell JHR, Van Essen DC (1983a) Functional properties of neurons in middle temporal visual area of the macaque monkey. II. Binocular interactions and sensitivity to binocular disparity. J Neurophysiol 49:1148-1167.

Maunsell JHR, Van Essen DC (1983b) The connections of the middle temporal visual area (MT) and their relationship to a cortical hierarchy in the macaque monkey. $\mathrm{J}$ Neurosci 3:2563-2586.
Mitchell DE (1966) Retinal disparity and diplopia. Vision Res 6:441451.

Newsome WT, Wurtz RH (1982) Identification of architectonic zones containing visual tracking cells in the superior temporal sulcus (STS) of macaque monkeys. Invest Ophthalmol Vis Sci [Suppl] 23:238.

Newsome WT, Wurtz RH, Komatsu H (1988) Relation of cortical areas MT and MST to pursuit eye movements. II. Differentiation of retinal from extraretinal inputs. J Neurophysiol 60:604-620.

Nikara T, Bishop PO, Pettigrew JD (1968) Analysis of retinal correspondence by studying receptive fields of binocular single units in cat striate cortex. Exp Brain Res 6:353-372.

Ogle KN (1952a) On the limits of stcrcoscopic vision. J Exp Psychol 44:253-259.

Ogle KN (1952b) Disparity limits of stereopsis. Arch Ophthalmol (Copenh) 48:50-60.

Pettigrew JD, Nikara T, Bishop PO (1968) Binocular interaction on single units in cat striate cortex: simultaneous stimulation by single moving slits with receptive fields in correspondence. Exp Brain Res 6:391-410.

Poggio GF, Fischer B (1977) Binocular interaction and depth sensitivity in striate and prestriate cortex of behaving rhesus monkey. $\mathbf{J}$ Neurophysiol 40:1392-1405.

Poggio GF, Talbot WH (1981) Mechanisms of static and dynamic stereopsis in foveal cortex of the rhesus monkey. J Physiol (Lond) 315:469-492.

Poggio GF, Motetr BC, Squatrito S, Trotter Y (1985) Responses of neurons in visual cortex (V1 and V2) of the alert macaque to dynamic random-dot stereograms. Vision Res 25:397-406.

Richmond BJ, Optican LM, Podell M, Spitzer H (1987) Temporal encoding of two-dimensional patterns by single units in primate inferior temporal cortex. I. Response characteristics. J Neurophysiol 57:132-146.

Robinson DA (1963) A method of measuring eye movement using a scleral search coil in a magnetic field. IEEE Trans Biomed Eng 10: $137-145$.

Roy J-P, Wurtz RH (1990) The role of disparity-sensitive cortical neurons in signalling the direction of self-motion. Nature 348:160 162.

Saito H-A, Yukie M, Tanaka K, Hikosaka K, Fukada Y, Iwai E (1986) Integration of direction signals of image motion in the superior temporal sulcus of the macaque monkey. J Neurosci 6:145-157.

Tanaka K, Saito H (1989) Analysis of motion of the visual field by direction, expansion/contraction, and rotation cells clustered in the dorsal part of the medial superior temporal area of the macaque monkey. J Neurophysiol 62:626-641.

Tanaka K, Fukada Y, Saito H (1989) Underlying mechanisms of the response specificity of expansion/contraction and rotation cells in the dorsal part of the medial superior temporal area of the macaque monkey. J Neurophysiol 62:642-656.

Ungerleider LG, Desimone R (1986) Cortical connections of visual area MT in the macaque. J Comp Neurol 248:190-222.

Van Essen DC, Maunsell JHR, Bixby JL (1981) The middle temporal visual area in the macaque: myeloarchitecture, connections, functional properties and topographic organization. J Comp Neurol 199: 293-326.

Warren WH, Hannon DJ (1990) Eye movements and optical flow. J Opt Soc Am A 7:160-169.

Westheimer G, Mitchell DE (1969) The sensory stimulus for disjunctive eye movements. Vision Res 9:749-755.

Westheimer G, Tanzman IJ (1956) Qualitative depth localization with diplopic images. J Opt Soc Am 46:116-117.

Wheatstone $C$ (1838) Contributions to the physiology of vision I. Philos Trans B371-B394.

Wurtz RH, Yamasaki DS, Duffy CJ, Roy J-P (1990) Functional specialization for visual motion processing in primate cerebral cortex. Cold Spring Harbor Symp Quant Biol 55:717-727. 